\title{
Silver nanoparticles as optical sensors
}

\author{
Chien Wang, Marta Luconi, Adriana Masi and Liliana Fernández \\ Universidad Nacional de San Luis - INQUISAL-CONICET \\ Argentina
}

\section{Introduction}

The use of silver nanoparticles (AgNPs) as analytical and bioanalytical sensors is receiving significant attention. This relevance arises from its unusual optical, electronic, and chemical properties (Schultz et al., 2000; Taton et al., 2000; Yguerabide \& Yguerabide, 1998). The optical excitation of the surface plasmon resonance (SPR) caused by a collective excitation of the conduction band electrons of the nanoparticle, produces an absorption with large molar extinction coefficients and relevant scattering, usually when the particle size is larger than a few tens of nanometers (Haes et al., 2004). Colloid suspensions display brilliant colors as a result of intense light absorption and scattering, a fact first recognized by Faraday (Faraday \& Philos, 1857), more than a century ago.

SPR is associated with the coupled oscillation of free electrons on the conduction band accompanying enhanced local electromagnetic field, which is intensely sensitive to surrounding medium conditions. When a nanoparticle is exposed to an electromagnetic wave, the electrons in the particle oscillate at the same frequency as the incident wave. Spectral characteristics of silver nanoparticles are strongly dependent on their size, shape, interparticle spacing and environment (b-Rao et al., 2002). Therefore, the geometry of noble metal nanoparticles would provide important control over linear and nonlinear optical properties (Bruzzone et al., 2005; b-Jiang et al., 2005; Roll et al., 2003).

Optical scattering has shown to be usefull in imaging methods to detect biosystems and has been applied to the diagnostics of cancer cells (Hirsch et al., 2003; El-Sayed et al., 2005).

Other potentialities are related to single-nanoparticle use as chemical and biological sensors (Cognet et al., 2003; McFarland \& Van Duyne, 2003); changes in the plasmonic resonance wavelength of maximum absorption or scattering are monitored as a function of changing the chemical and physical environment of the surface of the nanoparticles. The spectral response, SPR or scattering band, must be very sensitives to the changes in the refractive index of the surroundings. Many theoretical and experimental studies (Kelly et al., 2003; Gole \& Murphy, 2004) have been made on metal nanoparticles with different geometries with the purpose to find the best nanoparticle configuration and enhance the sensitivity of the plasmon resonance response. 


\section{Synthesis processes}

During the last decades, many synthesis methods have been reported for the preparation of AgNPs.

The processing of nanosized silver particles can be briefly classified as:

- Chemical reduction of silver ions (Fig.1) (Toshima et al., 1993; Liz-Marzan \& Philipse, 1995; Rivas et al., 2001; Pyatenko et al., 2005).

- Thermal decomposition in organic solvents (Esumi et al., 1990).

- $\quad$ Reversed micelle processes (Mafuné et al., 2000).

- $\quad$ Photoreduction (b-Zhou et al., 2001).

- Ultrasonic irradiation (Xiong et al., 2002), ${ }^{60} \mathrm{Co}-\gamma$-irradiation (Henglein \& Giersig, 1999) and microwave irradiation (Pastoriza-Santos \& Liz-Marzan. 2002).

No doubt, the main synthetic way is based on the dispersion and condensation processes. Among these methods, AgNPs with spherical, nanowire or nanoprism shapes with tunable sizes have been manufactured (Balan et al., 2007). In most cases, only a low concentration of silver colloids (several millimoles per liter or less) in the presence of suitable stabilizers has been obtained.

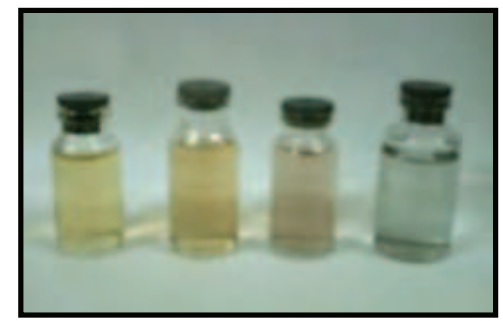

Fig. 1. AgNPs obtained by chemical reduction.

Experimental conditions as reagent concentrations, time and temperature of heating, cleanliness of glassware must be carefully controlled to achieve stable and reproducible colloids. The obtained products tend to form agglomerates and/or change the size or shape during the storage. As AgNPs are fairly unstable in solution (Luo \& Sun, 2007), the derivatization step is necessary to obtain monodispersed nanoparticles.

The most common strategy for the formation of stable nanoparticles in liquid is the use of a protective agent, which not only prevents their aggregation, but also results in functionalized particles (a-Rao et al., 2000). The choice of the capping agent is very critical because it determines the stability, solubility, reactivity, and even the size and shape of the nanoparticles during the synthesis. However, the stabilizers such as surfactants and ionic polymers cannot be easily removed from the surfaces of the silver colloids, which unavoidably affect the physicochemical properties of the resulting nanoparticles. Therefore, large-scale synthesis of nanosized silver particles using removable reductants and stabilizers is worthy of investigation. 


\section{Characterization of Silver Nanoparticles}

According to Mie theory (Petit et al, 1993), AgNPs spectra increase in intensity with the increase of size of NPs and decrese of broad of spectral band. Mock (Mock et al., 2002) studied absorption spectra of AgNPs with different morphologies, related with size, shape and wavelength of absorption using TEM; the results made evident that the more assimetric and greater size was the particle, the more bathochromic shift was shown.

Taking into account experimental dates, characterization of the nanoparticles to examine size, shape, and quantity is very important. A number of different measurement techniques can be used for this purpose; UV-visible spectroscopy is a valuable tool for study and structura, associated to scanning and transmission electronic microscopy (TEM), Atomic Force Microscopy (AFM), Scanning Electron Microscopy (SEM) and Dynamic Light Scattering (DLS). These techniques provide the image of a small piece of the sample, and this means that they give information about local properties by characterizing a few nanoparticles at a time (Sosa \& Noguez, 2003).

The applications of absorption spectroscopy are the most extensive. However, for examination of nanoparticles, the optical properties require an individually developed theory. Measured absorbance spectrum does not necessarily show the actual absorbance but the extinction of the light. The extinction is both the absorbed and the scattered light from the particles.

SEM is a valuable instrument, when high-resolution images of the surface is desired. The microscope measures the electrons scattered from the sample. Electrons are accelerated by an electric potential varying wavelength at shorter than the one of photons. SEM is capable of magnifying images up to 200.000 times achieving high resolution pictures of the surface and determining the size distribution of nanoparticles.

AFM is an instrument capable of measuring the topography of a given sample. A nanosized tip attached on a cantilever is traced over the sample and a $3 \mathrm{D}$ image of the sample topography is generated on a computer.

\section{Analytical and bioanalytical sensors}

\subsection{Colorimetric assays}

Colorimetric assays based on the unique surface plasmon resonance properties of metallic nanoparticles have showed to be very useful in the analysis of biomolecular and metal ions; they have received considerable attention due to their simplicity, high sensitivity, low cost, rapidity and they do not need the use of complecated apparatus.

As colorimetric assays, AgNPs have some advantages over gold NPs to a certain degree since they possess higher extinction coefficients relative to gold NPs of the same size. However, little attention has been paid to AgNPs based colorimetric assays, though sensitive and selective colorimetric detection has been reported using AgNPs functionalized with appropriate ligands. These limitations can be attributed to the following facts:

- Functionalization of AgNPs usually cause chemical degradation.

- AgNPs'surface could be easily oxidized.

Colorimetric analytical method using citrate-capped AgNPs has been developed and applied to berberine detection (b-Ling et al., 2008), an important anti-inflammatory drug for heart and intestinal disorders. Citrate-capped AgNPs with negatively charged surface can be symmetrically dispersed in water by the electrostatic repulse interaction of each particle. 
However, the presence of positive berberine would induce the aggregation of AgNPs, causing the color change of AgNPs suspension from yellow to green, and then to blue depending on the aggregation degree of AgNPs. The mechanism of color change and the effect of experimental conditions were studied using absorption and light scattering spectrometry. Under the optimum conditions, berberine hydrochloride can be detected from $0.05 \mu \mathrm{M}$ to $0.4 \mu \mathrm{M}$ visually based on the color alteration of the solution (LOD $=1.310^{-8} \mathrm{~mol}$ $\left.\mathrm{L}^{-1}\right)$. This colorimetric analytical method without use of expensive machines is so convenient, economy and speedy that it has flourishing prospects in analytical chemistry.

A new method for the synthesis of AgNPs based on the incomplete reduction of silver ions by UV light in presence of poly(methacrylic acid) (PMA) has been presented (a-Dubas \& Pimpan, 2008). The low power of the UV lamp provides a very slow kinetic of reaction which allows the preparation of purple solution of AgNPs.

UV-vis spectroscopy was used to monitor the kinetic of nanoparticles synthesis; their size and morphology were confirmed by transmission electron microscopy (TEM). The nanoparticles solution displays an absorbance maximum at $515 \mathrm{~nm}$ instead of the usually expected at $400 \mathrm{~nm}$ for spherical AgNPs. The unreacted silver is thought to be responsible for the color shift by forming an $\mathrm{Ag}^{+} / \mathrm{COO}^{-}$complex with the PMA stabilizing polyelectrolyte. The resulting solution displays a purple color which can be changed to yellow upon addition of ammonia; there are also medical interests in measuring this analyte in the body as indicator of disorder or disease. Based on this mechanism, an ammonia sensor has been proposed, showing a linear response in the range of 5-100 ppm.

A selective and sensitive method is proposed for detecting cysteine based on the color change of triangular silver nanoprisms at $\mathrm{pH} 5.5$ incubated for $3 \mathrm{~min}$ in boiling water bath (Wu et al., 2009). Only cysteine got a color change among all the 20 protein, including alanine, arginine, asparagines, aspartic acid, glutamine, glycine, histidine, isoleucine, leucine, lysine, methionine, phenylalanine, proline, serine, threonine, tryptophan, tyrosine and valine, forming amino acids. With increasing cysteine concentration, blue shift of the dipole plasmon resonance peak was obtained. With the increase of cysteine, the color sequentially changed from blue to bright blue, amaranth, salmon pink and orange. It was found that the blue shift of wavelength is in proportion to the logarithm of concentration of cysteine ( $\left.\log C_{\text {cysteine}}\right)$, fitting the equation of $\lambda_{\max }=471.3-93.1 \log \mathrm{C}_{\text {cysteine }}$ with correlation coefficient 0.9964. Considering that the color of the AgNPs is related to the size, shape, electron density on the colloidal surfaces and the refractive index of the surrounding medium, SEM images of the reaction between triangular silver nanoprisms and cysteine was measured; shape will transform to disk, so the method may serve as a new technique to control the size and shape of nanoparticles.

A sensitive, selective, simple and label-free colorimetric assay using unmodified AgNPs probes has been developed to detect enzymatic reactions (Wei et al., 2008). Enzymatic reactions concerning dephosphorylation and phosphorylation, specifically adenosine triphosphate (ATP) dephosphorylation by calf intestine alkaline phosphatase (CIAP) and peptide phosphorylation by protein kinase A (PKA), were chosen as model systems due to their significant importance to cellular regulation, cellular signaling, and biomedical applications. In the presented method, dephosphorylation and phosphorylation could be 
readily detected by the color change of AgNPs, with a detection limit of 1 unit $\mathrm{mL}^{-1}$ for CIAP and a detection limit of 0.022 unit $\mathrm{mL}^{-1}$ for PKA. This work is an important step toward a colorimetric assay using AgNPs and is a promise for enzyme assay in complex systems and for screening of different enzymes inhibitors in future.

Thompson (Thompson et al., 2008) has proposed the synthesis of oligonucleotide-silver nanoparticle (OSN) conjugates and demonstrated their use in a sandwich assay format. The OSN conjugates have practically identical properties to their gold analogues and due to their vastly greater extinction coefficient both visual and absorption analyses can occur at much lower concentrations.

A new one-pot protocol has been proposed for highly stable AgNPs modified with psulfonatocalix[n]arene $(n=4,8)$ (Xiong \& Lil, 2008). The obtained NPs were characterized by transmission electron microscopy, FT-IR and UV-vis spectroscopy. p-sulfonatocalix[4]arene modified AgNPs can be utilized as a novel colorimetric probe for optunal, allowing a rapid quantitative assay of optunal down to a concentration of $10^{-7} \mathrm{~mol} \mathrm{~L}^{-1}$, showing a great potential for application to real-time in situ detection of optunal and the possible mechanism is discussed.

AgNPs have been synthesized by reduction of silver nitrate in the presence of humic acids (HA) which acted as capping agents (b-Dubas \& Pimpan, 2008). In presence of sulfurazonethyl herbicide $(0,100,200,300,400,500 \mathrm{ppm})$, a variation in color of the nanoparticles solution from yellow to purple is produced. The effect of the humic acid concentration used in the nanoparticles synthesis was studied by varying the $\left[\mathrm{Ag}^{+}: \mathrm{HA}\right]$ ratio content from [1:1] to [1:100]. UV-vis spectroscopy was used to monitor the extinction spectra of AgNPs after the synthesis and in the herbicide sensing experiments. An average AgNPs size of $5 \mathrm{~nm}$ was confirmed by transmission electron microscope (TEM).

A novel beta-cyclodextrin-4,4'-dipyridine supramolecular inclusion complex-modified AgNPs has been synthesized for the colorimetric determination of $\mathrm{Yb}^{3+}$ ions in aqueous solution with high sensitivity (LOD 2 10-7 $\mathrm{mol} \mathrm{L}^{-1}$ ) (a-Han et al., 2009).

Cysteine modified AgNPs were prepared in aqueous solution, via one-pot protocol, and characterized by transmission electron microscopy (TEM), Fourier transform infrared (FTIR) and UV-vis spectroscopy (a-Li \& Bian, 2009). The nanoparticles provided a simple and rapid strategy to detect visually histidine (His) using $\mathrm{Hg}^{2+}$ solution (Fig. 2). The colorimetric sensor allows a rapidly quantitative assay of histidine down to the concentration of 3 $10^{-5} \mathrm{~mol} \mathrm{~L}^{-1}$.

A new spectrophotometric method for the determination of arsenic at a $\mathrm{mg} \mathrm{g}^{-1}$ level has been developed, based on the formation of AgNPs in anionic micellar medium and consecutive reduction of $\mathrm{Ag}(\mathrm{I})$ by arsine $\left(\mathrm{AsH}_{3}\right)$ generated from arsenic present in water (Pal $\&$ Maji, 2005). The magnitude of absorbance of yellow-coloured silver sol measured at $\lambda_{\max }=$ $395 \mathrm{~nm}$ was proportional to arsenic concentration in the sample with linear dynamic range of 0 to $0.5 \mathrm{mg} \mathrm{g}^{-1}\left(\mathrm{R}^{2}=0.998\right)$. Molar absorptivity equalled $4.9810^{-3} \mathrm{~L} \mathrm{~mol}^{-1} \mathrm{~cm}^{-1}$, and Sandell's sensitivity was $1.5010^{-2} \mu \mathrm{g} \mathrm{cm}^{-2}$. The proposed method is simple and provides 
reproducible results with standard deviations within $\pm 5 \%$, free of interferences for $\mathrm{Fe}^{2+}$ / $\mathrm{Fe}^{3+}, \mathrm{Ca}^{2+}, \mathrm{Mg}^{2+}, \mathrm{Sb}(\mathrm{III}), \mathrm{Se}(\mathrm{IV}), \mathrm{PO}_{4}^{3-}, \mathrm{SiO}_{3}=, \mathrm{NO}_{3}^{-}, \mathrm{Cl}^{-}, \mathrm{SO}_{4}{ }^{=}$, humic acid, pesticides/herbicides (such as 2,4-D, endosulfan, atrazine), etc.

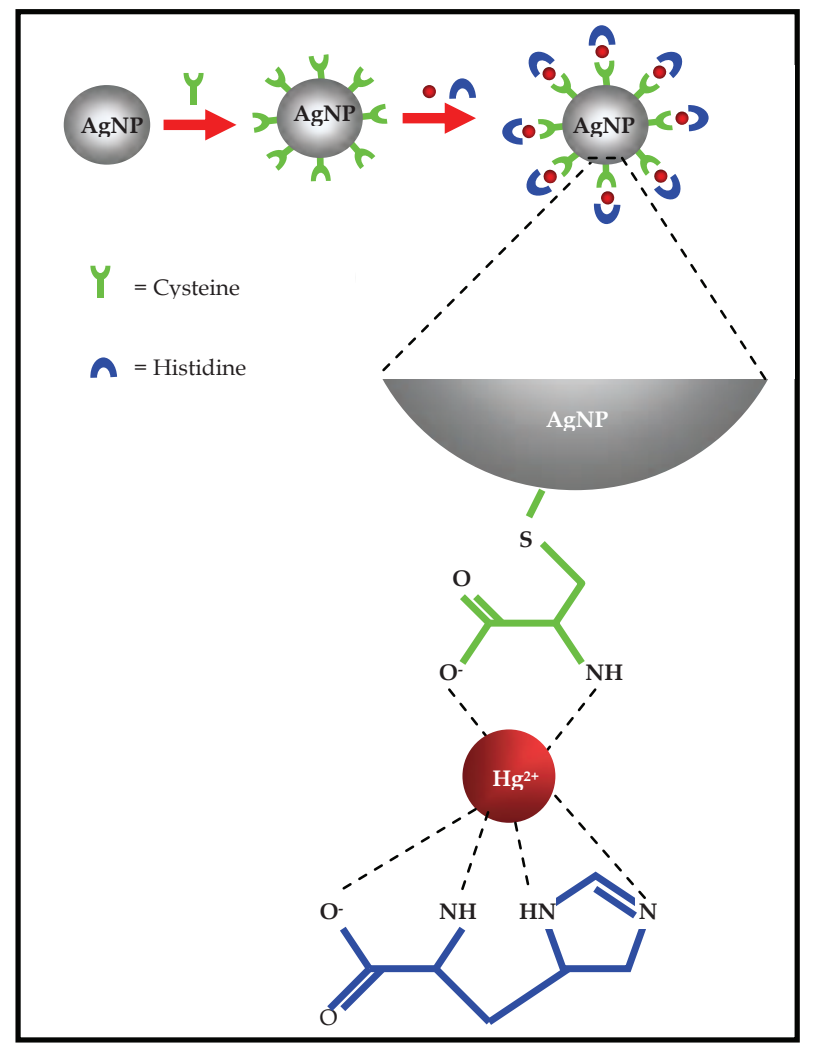

Fig. 2. Schematic representation of colorimetric sensor for histidine determination.

\subsection{Spectrofluorimetric Analysis}

Fluorescence detection is emerging as a powerful tool with wide applications in life sciences. This methodology allows in situ studies including binding of ligands such as a drug or hormone to a receptor, measurement of concentration of metabolites, study of structure, orientation, fluidity and distances between molecules. Yet in practical situations, where complex samples of biological origin must be used, such as in proteomics or clinical medicine, the presence of interfering background makes fluorescence detection more difficult and the need arises for the fluorescence signals to be amplified. Fortunately a physical nanoscale phenomenon exists which enables such amplification (a-Liu et al., 2006).

A good strategy to achieve improved sensitivity is the application of metal nanostructures in experimental protocols; these materials generally ensure high and/or spatially homogenous 
fluorescence enhancement. With the progress of nanotechnologies and the spectral theories, the luminescence properties of metal nanoparticles have been studied. But literatures about the nanoparticles-sensitized fluorescence are scarce (Zhao et al., 2008; Goldys \& Xie, 2008).

Among the noble metal nanoparticles, AgNPs have attracted more attention because of their advantage on various studies such as photosensitive components, catalysts, and surfaceenhanced Raman spectroscopy.

Liu et al. (b-Liu et al, 2007) prepared a kind of AgNPs by reaction of silver nitrate solution and ammonia gas. The strong fluorescence signal of the AgNPs solution can be quenched after the adding of the calf thymus DNA (ct-DNA) solution. Two excitation peaks appeared at the wavelengths of 239 and $314 \mathrm{~nm}$ respectively by emitting at $384 \mathrm{~nm}$. The synthetic method proposed, was based on the following reactions:

$$
\begin{aligned}
\mathrm{Ag}^{+}+\mathrm{OH}^{-} & \longrightarrow \mathrm{AgOH} \downarrow \\
2 \mathrm{AgOH} & \longrightarrow \mathrm{Ag}_{2} \mathrm{O}+\mathrm{H}_{2} \mathrm{O} \\
\mathrm{Ag}_{2} \mathrm{O} & \stackrel{h v}{\longrightarrow} \mathrm{Ag}
\end{aligned}
$$

The quenched NPs fluorescence intensity was linear with the concentration of ct-DNA in the range of 0.5 to $5.0104 \mathrm{ng} \mathrm{mL}^{-1}$ with a detection limit of $0.3 \mathrm{ng} \mathrm{mL}-1$.

The interferences of bovine serum albumin, amino acid and glucose were very weak. And among tested ions, $\mathrm{Mg}^{2+}, \mathrm{Zn}^{2+}, \mathrm{Fe}^{3+}, \mathrm{Ca}^{2+}, \mathrm{SO}_{4}=, \mathrm{Cl}^{-}$and I- can be allowed in relatively high concentrations, but $\mathrm{Cu}^{2+}$ and $\mathrm{PO}_{4}^{3-}$ ions can only be allowed in relatively low concentrations.

Zhao et al. (Zhao et al., 2008) studied the fluorescence of terbium(III) when it is excited in the presence of ciprofloxacin (CPLX) in aqueous solution. CPLX can form complex with $\mathrm{Tb}(\mathrm{III})$ ion and the intramolecular energy transfer from CPLX to $\mathrm{Tb}$ (III) takes place when excited. The maximum fluorescence emission band of the terbium ion is located at $545 \mathrm{~nm}$ with $\lambda_{\mathrm{ex}}=272 \mathrm{~nm}$, but this intensity obviously increases when the AgNPs are added to the $\mathrm{Tb}(\mathrm{III})-\mathrm{CPLX}$ system. This result indicates that AgNPs can promote the energy transfer between $\mathrm{Tb}(\mathrm{III})$ and CPLX. The size of the AgNPs affects the total intensity and is most enhanced by them at $\mathrm{pH}$ 6.0. The relative intensity is proportional to the concentration of CPLX. Based on this phenomenon, a new method for the determination of CPLX was developed by using a common spectrofluorometer to measure the intensity of fluorescence. The calibration graph for CPLX is linear in the range of $3.010^{-9}$ to $1.010^{-5} \mathrm{~mol} \mathrm{~L}^{-1}$. The detection limit is $8.510^{-10} \mathrm{~mol} \mathrm{~L}^{-1}$. The method was applied satisfactorily to the determination of CPLX in tablets and capsules. Their results showed that AgNPs with certain size and concentration can enhance the fluorescence.

Actually, luminescence methods for determining polycyclic aromatic hydrocarbons (PAHs), including adsorption-luminescence ones, are among the most sensitive methods. Nanosized organized media, including surfactant-modified noble metal nanoparticles, deserve special attention. Surfactants are most frequently used in the synthesis of noble metal nanoparticles for their stabilization and for the characteristic of modifying not only the properties of the test solution, but also those of the adsorbent surface A procedure for the synthesis of hydrophobic AgNPs in two-phase water organic emulsions was developed by Olenin et al. 
(a-Olenin et al., 2008; b-Olenin et al., 2009), in which silver nitrate was reduced with sodium borohydrate in an aqueous solution followed by their transfer into the organic phase using $\mathrm{CTAB}$ as a phase transfer catalyst. When small amounts (few $\mu \mathrm{L}$ ) of the chemically modified AgNPs sol were added to a dilute pyrene solution, the violet fluorescence intensity of pyrene decreased proportionally to the concentration of the nanoparticles added, and fluorescence with $\lambda_{\max }=440$ and $470 \mathrm{~nm}$ typical for pyrene excimers was observed in the long-wavelength region. The chemically modified AgNPs can be used as an adsorbent for preconcentrating pyrene from dilute $\mathrm{n}$-hexane solutions followed by the direct luminescence determination, at room temperature, in the adsorbent matrix at concentrations below $0.01 \mathrm{~g}$ $\mathrm{mL}^{-1}$ in test solutions.

Shang et al. (Shang et al., 2009) developed a sensitive fluorescent method for detecting cyanide based on the inner filter effect (IFE) of AgNPs (Fig. 3). The method proposes to use the powerful absorption of AgNPs to produce a tune in the emission and excitation of an isolated fluorescence indicator, which occurs in the IFE-based fluorescent assays. In the presence of cyanide, the absorber AgNPs dissolves gradually and leads then to recovery the IFE-decreased emission of the fluorophore. The method can detect cyanide with good selectivity over other common anions and ranging from $5.010^{-7}$ to $6.010^{-4} \mathrm{~mol} \mathrm{~L}^{-1}$ with a detection limit of $2.510^{-7} \mathrm{~mol} \mathrm{~L}^{-1}$. It compares favorably with other reported fluorescent methods and has further application in cyanide-spiked water samples with a recovery between 98.2 and $101.4 \%$.

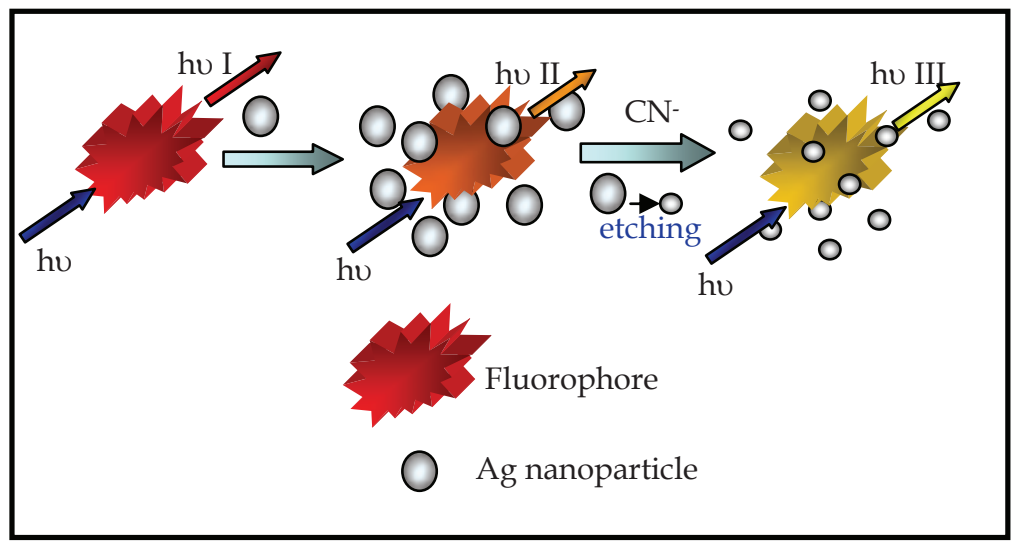

Fig. 3. Schematic representation of AgNPs-cyanide determination by IFE.

A sensitive and selective fluorimetric sensor for the assay of ascorbic acid using AgNPs as emission reagent was proposed by Park et al. (Park et al., 2009). AgNPs were prepared by reaction of silver nitrate solution and ammonia gas in aqueous-gaseous phase. AgNPs were used as a fluorescence probe for the assay of ascorbic acid using its quenching effect on the emission of AgNPs. They proposed that this effect was due to the complexation between ascorbic acid and AgNPs and established the quenching mechanism by Stern-Volmer law. The quenched fluorescence intensity was linear with the concentration of ascorbic acid in the range of $4.110^{-6}$ to $1.010^{-4} \mathrm{~mol} \mathrm{~L}^{-1}(\mathrm{r}=0.9985)$ with a detection limit of $1.010^{-7} \mathrm{~mol} \mathrm{~L}^{-1}$. 
The RSD for repeatability of the sensor for the assay of ascorbic acid concentration of 3.0 10-5 and $4.010^{-6} \mathrm{~mol} \mathrm{~L}^{-1}$ was found to be 1.5 and $1.3 \%$, respectively. The method was applied to the determination of ascorbic acid in vegetables and vitamin $C$ tablets.

\subsection{Methodologies based on scattering phenomena}

Investigations on light-scattering properties of nanomaterials and their application in analysis have been going on for more than 10 years (a-Ling et al., 2009). Yguerabide and Yguerabide (Yguerabide \& Yguerabide, 1998) anticipated the potential applications of these particles in biochemical assay and cell biology. Under appropriate light, AgNPs of $40 \mathrm{~nm}$ in diameter scatter blue light. These particles could potentially be used in biochemical assay and cell imaging as fluorescent analogs. The light-scattering properties of new nanomaterials (van Dijk et al., 2006; a-Pan et al., 2007) in different composition, size and shape have greatly attracted the attention of analysts, so the applications of nanomaterials for analytical purposes have grown dramatically. This topic constitutes an atractive approach which is in incipient development because of the unique advantages of NPs of colorful light-scattering properties, comparable to optical probes with various fluorescent dyes.

AgNPs open exciting new ways to create efficient optical probes based on the strongly enhanced spectroscopic signals that can occur in their local optical fields. One of the most impressive effects associated with local optical fields is surface-enhanced Raman scattering (SERS) (Otto, 1984; Moskovits, 1985; Campion \& Kambhampati, 1998; b-Kneipp et al., 1999). This technique is a form of Raman spectroscopy based on the interaction of the incident light with a molecule adsorbed onto the roughened metal surface. Derived from Raman spectroscopy, there are other interesting techniques employing AgNPs as substrate, such as surface-enhanced resonance Raman scattering (SERRS), surface-enhanced Raman optical activity (SEROA) and tip-enhanced Raman spectroscopy (TERS) (Pettinger et al., 2002; aKneipp et al., 2006).

Similar to IR, Raman spectroscopy (RS) yields detailed information about molecular vibrations. These kind of molecular motions are very sensitive to strength and types of chemical bonds. Therefore vibrational spectroscopy techniques are useful not only in identifying molecules but also reflect changes in the surrounding of the molecules and are thus, helpful in studying intra- and inter molecular interactions.

While infrared spectroscopy is based on absorption, reflection and emission of light, RS is based on inelastic scattering of radiation usually in the visible of near-infrared region by a solid, liquid or gaseous sample. In this context, scattering occurs due to collisions between photons and molecules (Fig. 4).

Irradiation of light with the frequency $v_{0}$ upon a certain molecule transfers a number of photons with the energy $\mathrm{E}=\mathrm{hv}_{\mathrm{o}}$ (Fig. 5). For instance, laser light having a wavelength of 500 $\mathrm{nm}$ and an optical output of $1 \mathrm{~W}$ emits approximately $2.510^{18}$ photons per second. These photons include photons colliding with molecules as well as those that pass without interacting with molecules. When carbon tetrachloride, which is a transparent liquid, is irradiated, it was found that about $10^{13}$ through $10^{15}$ photons collide with a molecule and change their directions among a total of $2.510^{18}$ photons. Most photons colliding with molecules do not change their energy after the collision (elastic collision) and the ensuing radiation is called Rayleigh scattering. Therefore, Rayleigh scattering consists of scattered photons which have the same frequency as the incident light, discussed in further section. 
Only a very small number of the photons that impact on the molecule, exchanges energy with them during the course of the collision (inelastic collision). Scattering phenomenon in which incident photons exchange energy with a molecule is known as RS. Depending on frequency having the scattered light after colliding with molecule it could be Stokes RS or anti-Stokes RS. If an incident photon delivers a quantum (hv) of energy to the molecule, and the energy of the scattered photon is reduced to $h\left(v_{0}-v\right)$, the scattering phenomenon is known as Stokes RS. Otherwise, when an incident photon receives the hu energy from the molecule, the energy of the scattering photon rises to $h\left(v_{0}+v\right)$, it is known as anti-Stokes RS.

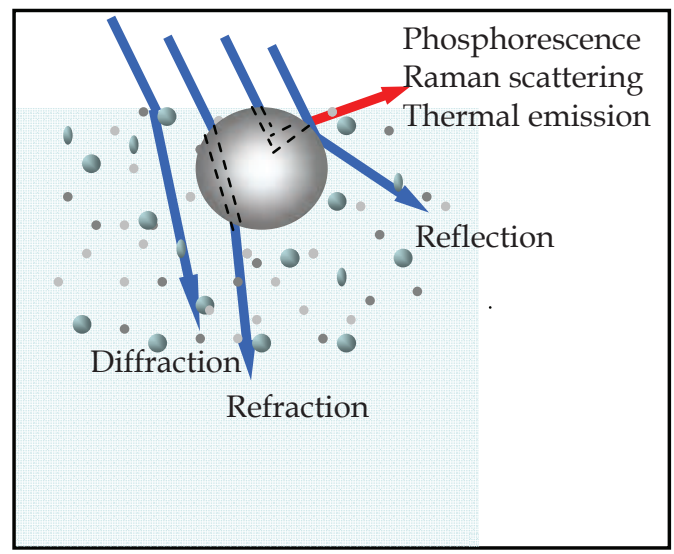

Fig. 4 Optical phenomena in the interphase air/aqueous AgNPs solution.

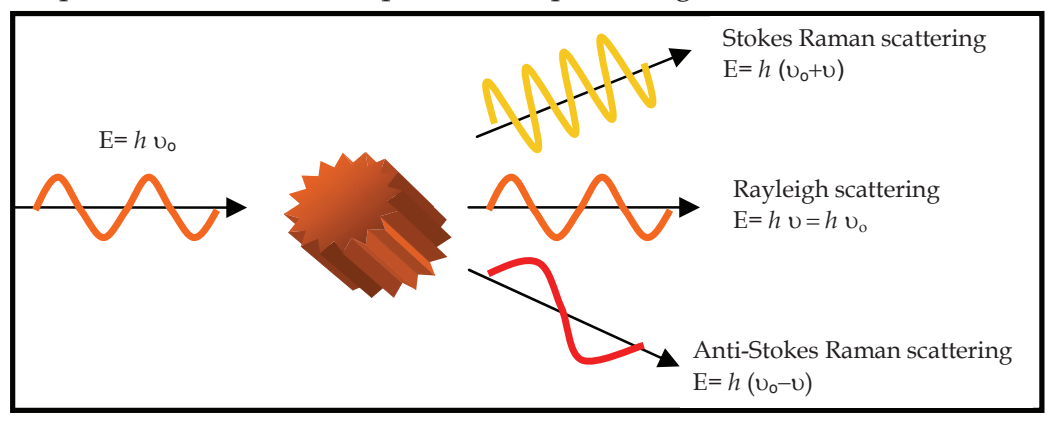

Fig. 5. Scattering phenomena.

The change in wavelength that is observed when a photon undergoes RS is attributed to the excitation (or relaxation) of vibrational modes of a molecule. Because of the diverse functional groups have different characteristic vibrational energies; every molecule has a unique Raman spectrum. Therefore, RS is a vibrational spectroscopic technique complementary to IR spectroscopy, but excitation and emission involve higer-energy photon similar to those used in electronic absorption and fluorescence spectroscopy.

It should be stressed that the basic feature of RS is scattering, which can occur at any wavelength. There is a change in the direction of the light, but no photon annihilation takes place as in an electronic absorption or fluorescence process. The selection rules are very 
different from those in IR: Raman signals are associated with vibrations that cause a change in polarizability.Even so, RS cross sections are typically 14 orders of magnitude smaller than those of fluorescence; therefore, the Raman signal is several orders of magnitude weaker than the fluorescence emission in most cases. In fact, many materials are not readily suited to conventional RS. These include dyes that fluoresce in the same spectral range as their Raman emission, so that the useful Raman spectrum is masked overwhelmingly.

Due to the inherently small intensity of the Raman signals, the limited sensitivity of available detectors, the intensity of the excitation sources, and the potential interferences from the substances which fluoresce, the applicability of RS has been restricted for many years. However, its utility as an analytical technique improved with the advent of the laser and the evolution of photon detection technology. Another approaching of the technique is the selection of excitation wavelength close to an electronic absorption band of the chromophore. When the overlapping of molecular absorption band with the laser wavelength occurs, the intensity of the normal Raman scattering can be enhanced by several orders of magnitude. This is known as Resonance Raman Scattering (RRS); while smaller is the frequency difference between laser and electronic transition, stronger is the RRS intensity. Since the unique expected resonance effects, are thouse produced when the laser line coincides with an electronic absorption, RRS combines sensitivity and selectivity. In principle, it enables one to selectively observe a chromophoric solute in a dilute solution or study a particular Raman scatter in a complex matrix.

\subsubsection{Surface-enhanced Raman Scattering}

In 1977, Jeanmaire and Van Duyne demonstrated that the magnitude of the RS signal can be greatly enhanced when the scatterer is placed on or near a roughened noble-metal substrate (Jeanmaire \& Van Duyne, 1977). This enhanced scattering process is known as surfaceenhanced Raman (SER) scattering, a term that emphasizes the key role of the noble metal substrate in this phenomenon. A number of different metals such as silver, gold, copper and aluminium can be used to provide the optically active surface (Campion \& Kambhampati, 1998; b-Kneipp et al., 1999); however, silver tends to give the largest enhancement factors using visible excitation wavelengths. Even though the exact mechanism of the enhancement effect of SERS is still a matter of debate in the literature, there are two primary theories which explain the phenomenon.

The first one uses plasma resonance model related to the optical properties of free-electronlike metals. Known as electromagnetic theory, it relies upon the excitation of localized surface plasmons (LSP) on nanoscale roughness features of metal substrate when it is irradiated by light. The excited LSP provides electromagnetic fields in order that when the Raman scatterer is subjected to these fields, the magnitude of the induced dipole increases. Taking account that the selection rules of Raman effect for a molecule are determined by its polarizability, accordingly, the intensity of the inelastic scattering increases (Raman scattering) when its polarizability increases.

The field enhancement becomes greatest when the plasmons frequency $\left(\omega_{p}\right)$ is in resonance with the radiation. In this instance, the LSPR (localized surface plasmons resonance) provides strong electromagnetic fields which leads to great enhanced Raman scattering from those molecules close to the metal surface. Although it is difficult to determine the extent of the enhanced fields from the nanostructured surface, theoretical calculations for well-characterized nanoparticles suggest that these fields degrade exponentially with a 
characteristic decay length of $\sim 2 \mathrm{~nm}$ (Schatz \& Van Duyne, 2002). The three major strategies for confining a SERS analyte within the electromagnetic fields are physisorption, chemisorption, and partitioning via a self-assembled monolayer (Fig. 6).

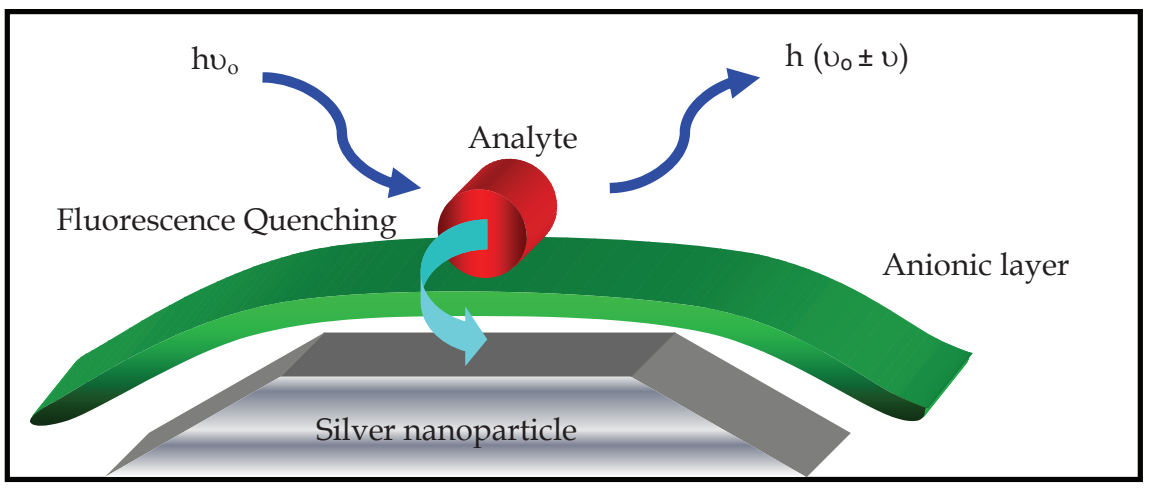

Fig. 6. SERS phenomena.

While the electromagnetic theory of enhancement can be applied regardless of the molecule studied, it does not fully explain the magnitude of the enhancement observed in many systems. Therefore, a second approach is based on the concept of the "active sites" at the metal surface. This model is known as chemical theory, due to the fact that for many molecules, often those with alone pair of electrons, with which the molecules can bond to the surface, a distinctly different mechanism of enhancement has been described, which does not involve surface plasmons. Through the formation of charge-transfer complexes between the metal and the molecules occupying these active sites induces enhanced Raman scattering effect.

Explanation using molecular orbital theory, the HOMO (Highest occupied molecular orbital) to LUMO (Lowest unoccupied molecular orbital) transition for many molecules requires much more energy than the infrared or visible light which is typically involved in Raman experiments. When the HOMO and LUMO of the adsorbate fall symmetrically about the Fermi level (chemical potential) of the metal surface, light of half energy can be employed to make the transition. This phenomenon takes place because the metal acts as a charge-transfer intermediate. Thus, a spectroscopic transition that might normally take place in the UV can be excited by visible light. However, chemical theory only applies for species which have formed a bond with the surface, so it clearly cannot explain the observed signal enhancement in all cases, while the electromagnetic theory can be applied even for molecules physisorpbed at a distance of more than $10 \AA$ from the surface (Campion \& Kambhampati, 1998).

The SERS technique has many advantages: because of it is a vibrational spectroscopy technique, a SER spectrum provides much more information about molecular structure and the local environment than an electronic spectroscopy technique, such as fluorescence. As the SERS analyte must be on or near a noble metal, which provides nonradiative pathways for the decay of excited states, fluorescence interference is strongly quenched. This becomes a solution for analysis of many fluorescent chromofores which were not possible to be analyzed by traditional Raman spectroscopy. Also, minor changes in the orientation of an 
adsorbate can be discerned, because slight variations yield measurable shifts in the locations of SERS spectral peaks.

Furthermore, the abrupt decay of the electromagnetic fields ensures that only adsorbed molecules on or near the noble-metal substrate (within $4 \mathrm{~nm}$ ) are probed. This quality makes SERS an ideal tool for surface studies, trace analyses, or biomolecular interactions.

Anothers distinctive advantages are the fact that water exhibits extremely weak SERS signals and AgNPs substrates are compatible to aqueous-phase. This makes the SERS technique employing AgNPs well suited for analysis performed on molecules in aqueous media. Therefore, for in vivo and in vitro biological studies it is found an increasingly interest as bioanalytical and bioimaging tool.

One of the disadvantages on SERS is the fact that not all analytes are good Raman scatterer. Therefore, this technique encounters an important limitation due to the great number of compound which gives a poor Raman signal. However, this hitch is resolved easily by employing SERRS as an alternative surface-enhanced Raman scattering technique.

To achieve SERRS, a laser excitation frequency is chosen to coincide with the absorption frequency of the chromophore (electronic absorption band). The molecular resonance is given as result of the wavelength overlapping between molecular electronic absorption band and the laser frequency, giving RRS phenomenon. This combination of RRS with resonance surfaceenhanced fenomenon provides to SERRS the extreme sensitivity. A number of chromophores, which possess high Raman cross sections, can be attached to analytes with poor Raman signal. The formed complex is then adsorbed onto a suitably roughened metal surface and a laser source is chosen to create the respective resonances, giving a spectral enhancement with minimum background. Accordingly, this technique can be applied for analytes which in otherwise, cannot be determined by RS or SERS. Compared to SERS, SERRS appears to operate more effectively at low concentrations. However, SERS is more molecularly specific and nearly as effective at enhancing the scattering process at higher concentrations.

Total SERS/SERRS enhancement factors can reach 14 orders of magnitude, which produce nonresonant/resonant surface-enhanced Raman signals to a level comparably to or even better than fluorescence.

Unlike fluorescence, which produces relatively broad bands, Raman scattering as a vibrational, i.e., structure-specific method yields a unique spectrum composed of several narrow spectral lines, resulting in well-distinguishable spectra even for similar molecules. This lead to the development of SEROA, a novel method based on Raman optical activity (ROA) combined to surface-enhanced phenomenon for the analysis of enantiomers. ROA effect provides important information on molecular structure on the basis of differences in Raman spectra generated by left and right circularly polarized light. ROA is particularly sensitive to chirality, a molecular property that can be used to characterize polymeric assemblies as well as small molecules. Hence, the secondary structures of proteins and polyribonucleotides and also their building blocks can be discriminated. This includes individual amino acids, nucleosides, and many other biosynthetic precursors and small molecules of biological relevance which are optically active. Therefore, SEROA provide high spectral specificity, multiplex capabilities, and photostability for enantiomers determinations (Cao et al., 2002; Docherty et al., 2004).

Recently, SERS employing AgNPs as substrate to provide active optical surface has been used extensively as a signal transduction mechanism in biological and chemical sensing. Examples are cited in Table 1 and 2. 


\begin{tabular}{|c|c|c|c|}
\hline Methodology description & Analyte(s) & $\begin{array}{c}\text { Analytical } \\
\text { performance }\end{array}$ & References \\
\hline $\begin{array}{l}\text { Label-free protein } \\
\text { determination }\end{array}$ & $\begin{array}{l}\text { Lysozyme } \\
\text { Catalase }\end{array}$ & $\begin{array}{c}\text { LOD } \\
5 \mu \mathrm{g} \mathrm{mL}^{-1} \\
0.05 \mu \mathrm{g} \mathrm{mL}^{-1}\end{array}$ & $\begin{array}{l}\text { c-Han et. al., } \\
2009\end{array}$ \\
\hline $\begin{array}{l}\text { Colloidal silver staining } \\
\text { for Western Blot label-free } \\
\text { protein determination }\end{array}$ & $\begin{array}{l}\text { Bovine serum } \\
\text { albumin }\end{array}$ & $\begin{array}{c}\text { LOD } \\
2 \mathrm{ng} / \text { band }\end{array}$ & $\begin{array}{l}\text { d-Han et al., } \\
2008\end{array}$ \\
\hline Intracellular $\mathrm{pH}$ sensor & $\mathrm{H}^{+}$(range 6-8) & --- & Talley et al., 2004 \\
\hline $\begin{array}{l}\text { Multiplex imunoassay } \\
\text { for cellular proteins uing } \\
\text { fuorescent-SERS dots by } \\
\text { fluorescence bright field } \\
\text { imagine }\end{array}$ & $\begin{array}{c}\text { CD34, Sca-1, and SP- } \\
\text { C }\end{array}$ & Identification & Woo et al., 2009 \\
\hline $\begin{array}{l}\text { Specific virus DNA } \\
\text { sequence } \\
\text { determination }\end{array}$ & $\begin{array}{c}\text { Human } \\
\text { immunodeficiency } \\
\text { virus type } 1 .\end{array}$ & Identification & $\begin{array}{l}\text { Wabuyele et al., } \\
2005\end{array}$ \\
\hline $\begin{array}{l}\text { In situ measurements for } \\
\text { chemical analysis of } \\
\text { biofilms }\end{array}$ & $\begin{array}{l}\text { Multispecies } \\
\text { biofilms; multiplex } \\
\text { components }\end{array}$ & --- & Ivleva et al., 2008 \\
\hline $\begin{array}{c}\text { Kinetics monitoring } \\
\text { endospore germination } \\
\text { by Mirror sandwich SERS } \\
\text { substrates }\end{array}$ & $\begin{array}{c}\text { L-alanine; } \\
\text { different } \\
\text { temperatures }\end{array}$ & --- & $\begin{array}{l}\text { Jacquitta et al., } \\
\qquad 2006\end{array}$ \\
\hline $\begin{array}{l}\text { Ratio-method using } \\
\text { isotopically labeled } \\
\text { internal standard }\end{array}$ & Creatinine & $\begin{array}{c}\text { LOD } \\
11.4 \mu \mathrm{g} \mathrm{mL}^{-1}\end{array}$ & $\begin{array}{l}\text { Stosch et al., } \\
2005\end{array}$ \\
\hline $\begin{array}{l}\text { bis-acridinium dication } \\
\text { lucigenine as molecular } \\
\text { assembler }\end{array}$ & $\begin{array}{c}\text { Organochlorine } \\
\text { pesticide endosulfan }\end{array}$ & $\begin{array}{c}\text { LOD } \\
20 \mu \mathrm{g} \mathrm{L}^{-1}\end{array}$ & $\begin{array}{l}\text { Guerrini et al., } \\
2008\end{array}$ \\
\hline Ion-sorption on surfaces & Uranyl ion & $\begin{array}{c}\text { LOD } \\
20 \mathrm{ng} \mathrm{mL-1}^{-1}\end{array}$ & $\begin{array}{l}\text { Bhandari D. et } \\
\text { al., } 2009\end{array}$ \\
\hline $\begin{array}{l}\text { Heat-induced SERS } \\
\text { sensing }\end{array}$ & Glutathione & $\begin{array}{l}\text { LOD } \\
50 \mathrm{nM}\end{array}$ & $\begin{array}{l}\text { Huang et al., } \\
2009\end{array}$ \\
\hline $\begin{array}{l}\text { SERS microflow cell for } \\
\text { study of pigment within } \\
\text { cyanobacteria from } \\
\text { samples of rock }\end{array}$ & Scytonemin pigment & $\begin{array}{l}\text { LOD } \\
2 \mathrm{nM}\end{array}$ & $\begin{array}{l}\text { Wilson et al., } \\
2007\end{array}$ \\
\hline
\end{tabular}

Table 1. Analytical applications of SERS phenomenon. 
For detecting some biomolecules, a protocol for adding an aggregation agent to induce strong SERS has been used (Fig. 7). At pH lower than the protein isoelectric point, all the target proteins carry net positive charges, so these proteins can be adsorb on silver surfaces by electrostatic interactions and other interactions already mentioned. Accordingly, multiple interaction sites of an individual protein may bridge two or more silver nanoparticles and induce the subsequent SERS.

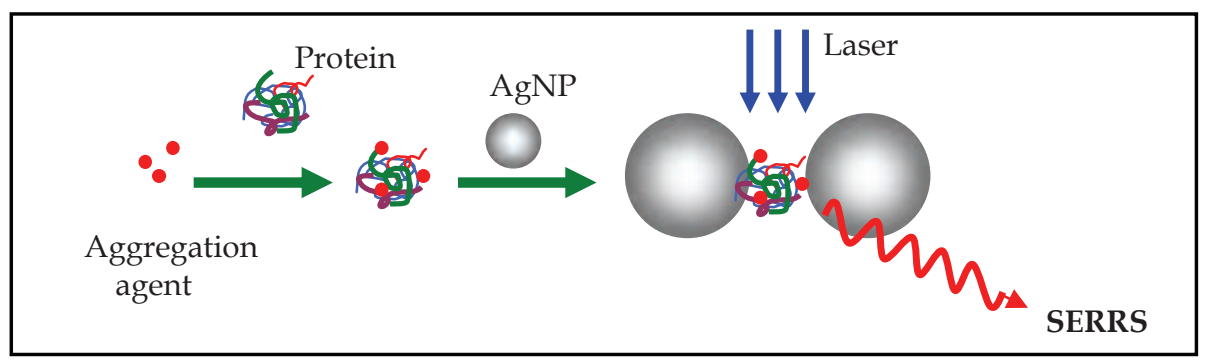

Fig. 7. SERS/SERRS protocol for biomolecule detection in presence of aggregation agent.

Moreover, immobilized silver colloidal nanoparticles have been used as a SERS substrate to perform microspectroscopic imaging. This technique was successfully applied for cancer cells imaging and other bio-molecules. As biosensor, is a highly sensitive tool for in-vivo study of many living system. The most critical aspect of performing a SERS experiment is the fabrication of the noble-metal substrates.

\begin{tabular}{|c|c|c|c|}
\hline Methodology description & Analyte(s) & $\begin{array}{c}\text { Analytical } \\
\text { performance }\end{array}$ & References \\
\hline $\begin{array}{l}\text { Fluorescein isothiocyanate } \\
\text { linked immunoabsorbent } \\
\text { assay }\end{array}$ & Human IgG & $\begin{array}{c}\text { LOD } \\
0.2 \mathrm{ng} \mathrm{mL}^{-1}\end{array}$ & b-Han et al., 2008 \\
\hline $\begin{array}{l}\text { Multiplex detection of } \\
\text { DNA sequences }\end{array}$ & $\begin{array}{l}\text { Methicillin- } \\
\text { resistant } \\
\text { Staphylococcus } \\
\text { aureus }\end{array}$ & $\begin{array}{l}\text { LOD } \\
10^{-12} \mathrm{~mol} \mathrm{~mL}^{-1}\end{array}$ & $\begin{array}{l}\text { MacAskill et al., } \\
2009\end{array}$ \\
\hline $\begin{array}{l}\text { Colloidal silver Staining } \\
\text { for Western Blot label-free } \\
\text { protein determination }\end{array}$ & Myoglobin & $\begin{array}{c}\text { LOD } \\
4 \mathrm{ng} / \text { band }\end{array}$ & d-Han et al., 2008 \\
\hline $\begin{array}{c}\text { Rhodamine-labeled } \\
\text { oligonucleotide sequence } \\
\text { in a bead-based lab-on-a- } \\
\text { chip format }\end{array}$ & $\begin{array}{l}\text { Nucleic acid } \\
\text { sequences of } \\
\text { Chlamydia } \\
\text { trachomatis }\end{array}$ & $\begin{array}{c}\text { LOD } \\
20.6 \mathrm{nM}\end{array}$ & $\begin{array}{c}\text { Monaghan et al., } \\
2007\end{array}$ \\
\hline $\begin{array}{c}\text { Overtones and } \\
\text { combinations in single- } \\
\text { molecule spectra }\end{array}$ & $\begin{array}{l}\text { Perylenetetracar } \\
\text { boxylic diimides }\end{array}$ & $\begin{array}{c}\text { Single molecule } \\
\text { level }\end{array}$ & Goulet et al., 2003 \\
\hline
\end{tabular}




\begin{tabular}{|c|c|c|c|}
\hline \multirow{6}{*}{$\begin{array}{c}\text { Detection and } \\
\text { characterization of } \\
\text { structurally similar } \\
\text { monosaccharides }\end{array}$} & ose & & \multirow{6}{*}{$\begin{array}{c}\text { Mrozek \& } \\
\text { Weaver, } 2002\end{array}$} \\
\hline & D-galactose & Identification & \\
\hline & D-mannose & & \\
\hline & D-ribose & "fingerprints" & \\
\hline & D-arabinose & with samples 5 & \\
\hline & $\begin{array}{l}\text { D-xylose } \\
\text { D-lyxose }\end{array}$ & $\mu$ & \\
\hline
\end{tabular}

Table 2. Analytical applications of SERRS phenomenon.

\section{Single-molecule SERS and the future}

The early single-molecule detection with SERS was achieved by Nie and Kneipp groups independently at different experimental conditions. The Nie study included a correlated topographical and optical characterization of unaggregated AgNPs dosed with Rhodamine 6G (R6G) molecules. They hypothesized that only 1 of every 100-1000 nanoparticles is "optically hot" and that only 1 of every 10,000 surface sites on a "hot particle" has efficient enhancement (Nie et al., 1997). Accordingly, the single-molecule enhancement is 106-107 larger than the population-averaged enhancement.

Kneipp research group, on the other hand, probed small (100-150nm) silver colloid aggregates dosed with crystal violet molecules. The large single-molecule enhancement $\left(10^{14}\right)$ is hypothetically attributed to large electromagnetic fields generated by fractal-pattern clusters of silver colloid nanoparticles (d-Kneipp et al., 1997).

Since these two pioneering experiments, SERS has been used to detect single molecules of biologically significant compounds, such as adenosine monophosphate (c-Kneipp et al., 1998) and hemoglobin (Xu et al., 1999).

Although the entire SERS community is excited by the recent development of singlemolecule SERS, a new controversy surrounds the huge enhancement factors. Current hypotheses regarding the single-molecule enhancement mechanism center on the concept that SERS substrates have a small number of "hot spots", which are thought to occur at the junctions between two nanoparticles. Correlated single molecule SERS and topographical studies have clearly demonstrated that single-molecule SERS occurs only in compact aggregates of nanoparticles where these junctions may exist (Michaels et al., 2000). The large electromagnetic fields at the junction act as an optical trap for the Raman-active molecule and yield large scattering signals as well as enhanced photochemistry. The single-molecule SER spectra fluctuate on the time scale of $1 \mathrm{~s}$; this is a signature of the molecule moving in and out of the hot spot and changing its orientation. Theoretical modeling of the electromagnetic field between two nanoparticles separated by $\leq 1 \mathrm{~nm}$ reveals a surface junction excitation and the efficient interaction of the molecular wave function with the wave function of the excited metal surface (a-Jiang et al., 2003).

An encouraging method for generalizing SERS to a wide variety of substrates is the development of tip-enhanced Raman spectroscopy (TERS) (Pettinger et al., 2002). In this technique, the electromagnetic field enhancement is provided by the excitation of the LSPR of a scanning probe. This eliminates the need to use noble-metal substrates to observe SERS. The probe can be a scanning tunneling microscopy probe, a metal-coated atomic force microscopy probe, a tapered optical fiber with a nanoparticle or thin metal film at the tip, or any other nanoscale-sharpened metallic object. Because of the strongest field enhancement is 
localized to a small volume very close to the apex of the probe, TERS can potentially provide chemical information at a spatial resolution below the diffraction limit. Theoretical modeling of TERS has suggested that enhancement factors of $10^{7}$ and a spatial resolution of $<5 \mathrm{~nm}$ can be achieved (Richards et al., 2003).

\subsubsection{Rayleigh light scattering (RLS)}

Rayleigh (a-Rayleigh, 1871; b-Rayleigh, 1871), developed a theory of light scattering for small spherical particles which scatter but do not absorb light. Later, Mie (Mie, 1908), developed a more general theory of light scattering that applies to spherical particles of any size that can absorb as well as scatter light.

Rayleigh theory can be expressed as follow:

$$
I=\frac{16 \pi^{4} a^{6} n_{m e d}^{4} I_{0}}{r^{2} \lambda_{0}^{4}}\left|\frac{m^{2}-1}{m^{2}+2}\right|^{2} \sin ^{2}(\alpha)
$$

where $I_{0}$ is the intensity of incident monochromatic light, a is the angle between the detection direction $\mathbf{r}$ and the direction of polarization of the incident beam, $n_{\text {med }}$ is the refractive index of the medium surrounding the particle, and $m$ is the relative refractive index of the bulk particle material (refractive index of a macroscopic piece of the material of which the particle is composed divided by $n_{\text {med }}$ ) (Yguerabide \& Yguerabide, 1998).

The wavelength of the scattered light is the same as that of the incident light beam. The scattered light intensity $I$ depends on wavelength, and in general both $m$ and $n_{\text {med }}$ also depend on wavelength; $r$ is the distance between the particle and the position where the scattered light is detected.

There are strong analogies between fluorescence and light scattering, but also there are differences that must be taken into consideration, namely only ones:

- Light produced by a scattering process has the same wavelength as the incident light; fluorescence occurs at higher wavelengths than excitation process and the fluorescence spectrum profile is independent of incident light wavelength.

- $\quad$ Light scattered by a small spherical particle is completely polarizad; light emitted by a fluorescent solution is only partially polarizad.

- The excited state lifetime for light scattering is usually less than 10-11 s whereas fluorescence lifetimes are usually in the range of 1 to $300 \mathrm{~ns}$.

- Scattering intensity is not noticeably quenched; fluorescence intensity is sensitive to a variety of quenchers.

A simple and sensitive method for the determination of nucleic acids has been established (a-Zhou et al., 2009) based on the further enhancement effect of resonance light scattering of AgNPs-fsDNA by $\mathrm{Al}(\mathrm{III})$. The results for the determination of plasmid DNA in actual samples are satisfactory. The interaction mechanism investigation indicates that fsDNA and AgNPs combine with $\mathrm{Al}(\mathrm{III})$ through electrostatic attraction and adsorption bridging action to form AgNPs-Al(III)-DNA aggregations. This method is very simple, rapid and effective for determination of nucleic acids, which may be suggested for further uses in biology and nanoscience. 
The RLS spectra were obtained by simultaneously scanning the excitation and emission monochromators over the range of $250-600 \mathrm{~nm}$ (i.e. $\Delta \lambda=0 \mathrm{~nm}$ ). The intensity of resonance light scattering was measured at the maximum wavelength $(398 \mathrm{~nm})$ in a $1 \mathrm{~cm}$ quartz cell, with the slit width at $10 \mathrm{~nm}$ for the excitation and emission. The enhanced RLS intensity of AgNPs-Al(III)-nucleic acids system was represented as $\Delta I=I_{R}-I_{R}{ }^{0}$, where $I_{R}$ and $I_{R}{ }^{0}$ were the RLS intensities of the systems with and without nucleic acids.

Under optimum conditions, there were linear relationships between the enhancing extent of RLS and the concentration of nucleic acids in the range of $1.010^{-9}-1.010^{-7} \mathrm{~g} \mathrm{~mL}^{-1}, 1.010^{-7}$ $2.010^{-6} \mathrm{~g} \mathrm{~mL}^{-1}$ for fish spermDNA(fsDNA), $1.010^{-9}-7.010^{-8} \mathrm{~g} \mathrm{~mL}^{-1}$ for calf thymusDNA (ctDNA) and $1.010^{-9}-1.010^{-7} \mathrm{~g} \mathrm{~mL}^{-1}$ for yeast RNA (yRNA). The detection limits $(\mathrm{S} / \mathrm{N}=3$ ) of fsDNA, ctDNA and yRNA were $4.110^{-10} \mathrm{~g} \mathrm{~mL}^{-1}, 4.010^{-10} \mathrm{~g} \mathrm{~mL}^{-1}$ and $4.510^{-10} \mathrm{~g} \mathrm{~mL}^{-1}$, respectively.

\subsubsection{Second order scattering (SOS)}

Second-order scattering (SOS), a phenomenon associated to fluorimetric determination, appears at the double wavelength of the exciting light. As SOS may interfere with fluorimetric measurement, it is always minimised off and eliminated as an unwanted phenomenon.

When a beam of parallel monochromatic light passes though a solution, an intensive radiation can also appear at half wavelength of the incident light, named "anti-double scattering" or "frequency doubling scattering" (FDS). FDS and SOS have been successfully applied to the determination of cations and cationic surfactants (b-Li et al., 2002).

The scattering intensity has been calculated to be:

$$
I\left(\lambda, \lambda_{\text {ex }}\right)=K b c f(d) f(\Delta \lambda) E_{\mathrm{m}}(\lambda) E_{\mathrm{x}}\left(\lambda_{\mathrm{ex}}\right)
$$

where $K$ is the ratio coefficient, $c$ the concentration of the scattering particle, $b$ the thickness of the cell, $d$ the size of the scattering particle, $\Delta \lambda$ the difference of excitation and emission wavelengths, $E_{\mathrm{m}}(\lambda)$ the intensity distribution of the scattering light, $E_{\mathrm{x}}\left(\lambda_{\mathrm{ex}}\right)$ is the excitation spectrum of the scattering light (Jiang et al., 2001).

When $\lambda_{e x}=(1 / 2) \lambda$, and $\lambda_{e x}=2 \lambda$, the $I \lambda$ relation curves are just the SOS and FDS spectra. That is:

$$
\begin{gathered}
I_{\mathrm{SOS}}=K b c f(d) f(\Delta \lambda) E_{\mathrm{m}}(\lambda) E_{\mathrm{x}}[(1 / 2) \lambda] \\
I_{\mathrm{FDS}}=K b c f(d) f(\Delta \lambda) E_{\mathrm{m}}(\lambda) E_{\mathrm{x}}(2 \lambda)
\end{gathered}
$$

Ding et al. (Ding et al., 2006) reported at first time, the effects of AgNPs on the SOS and fluorescence properties of $\mathrm{Tb}(\mathrm{III})$-quinolones (Qs) complexes in solution. The new determination method of quinolones was developed using a common spectrofluorometer. This field is in the beginnings, and many new opportunities for nanoparticles will arise in the coming decades.

The SOS intensity reached the maximum at $545 \mathrm{~nm}$ with $\lambda_{\mathrm{ex}}=274 \mathrm{~nm}$. All the SOS and fluorescence intensities $(\Delta \mathrm{I})$ were measured against the blank which was prepared by the same way, but without quinolones, and thus $\Delta I=I-I_{0}$ was obtained.

The size of the AgNPs was found that affect the SOS intensity and the energy transfer between $\mathrm{Tb}(\mathrm{III})$ and quinolones. When the size of the AgNPs in the system increases, the 
scattering intensity increases. Thus the selection of the appropriate diameter of AgNPs is very important. The results showed that:

- when the diameter of AgNPs was about $25 \mathrm{~nm}$, the SOS intensity was very low;

- when the diameter was approximate $70 \mathrm{~nm}$, the scattering of AgNPs was in the highest light and the SOS intensity was not proportional to the amount of quinolones (Qs);

- $\quad$ when the diameter was $45 \mathrm{~nm}$, the intensity was greatly enhanced and the relative intensity was in the linear range.

Therefore in the next experiments the size of $45 \mathrm{~nm}$ was chosen, that is, the concentration of reduced $\mathrm{AgNO}_{3}$ was $1.010^{-4} \mathrm{~mol} \mathrm{~L}-1$.

The concentration of AgNPs is associated with the aggregation degree. Thus AgNPs concentration directly affects the intensity of SOS and fluorescence. So selection of the concentration of AgNPs is necessary. The effect of AgNPs concentration on the intensity in the concentration range $1.010^{-8}-1.010^{-4} \mathrm{~mol} \mathrm{~L}^{-1}$ was studied. The results indicated that the largest enhancement appeared when $1.010^{-6} \mathrm{~mol} \mathrm{~L}^{-1}$ AgNPs was used. Species such as vitamin $\mathrm{B}_{1}$, uric acid, hemoglobin, myoglobin, $\mathrm{Fe}(\mathrm{III})$ and $\mathrm{Al}(\mathrm{III})$ have a relatively high interference. Dilution could be considered to minimize the interference in the application of urine samples.

The proposed method was applied to the determination of pipemidic acid (PPA) and lomefloxacin (LMFX) in tablets and urine of subjects over pharmacological treatment with these drugs with successfully results.

A new modified EDTA-AgNPs have been synthesized and characterized (Fig 8) (SEM, UVvis and fluorescence spectroscopy) (Wang et al., 2009). Through SEM images it could be confirmed that these EDTA-AgNPs were monodispersed in aqueous medium, instead of the agglomerated forms present before derivatized reaction. The fluorescent quenching and SOS decrease of these nanoparticles produced by presence of nitrate was studied. Quenching mechanism was proposed for SOS phenomenon. An innovative methodology was developed for ultra-trace nitrates quantification and successfully applied for its determination in commercial parenteral

solutions. The main advantage of the proposed method is the possibility of direct nitrates determination with very good accuracy, sensitivity and tolerance, without the need of previous reduction to nitrite, neither any previous treatment for samples used. The obtained results showed that AgNPs can be applied as optical sensor for nitrate determination.

During the synthesis of the AgNPs by conventional heating it was observed that after adding citrate, the color of solution changed from colorless to yellow, making evident the formation of colloidal silver (Fig. 9). The optimal reaction time was fixed at 6 min; when the time exceed the optimal, the reaction mix change to greenish grey.

SEM images show that, in this instance, the particles which were nearly spherical were not well separated and stuck together to form many small groups. This typical behavior has been reported by other researchers (He et al., 2004; Jiang et al., 2005). 


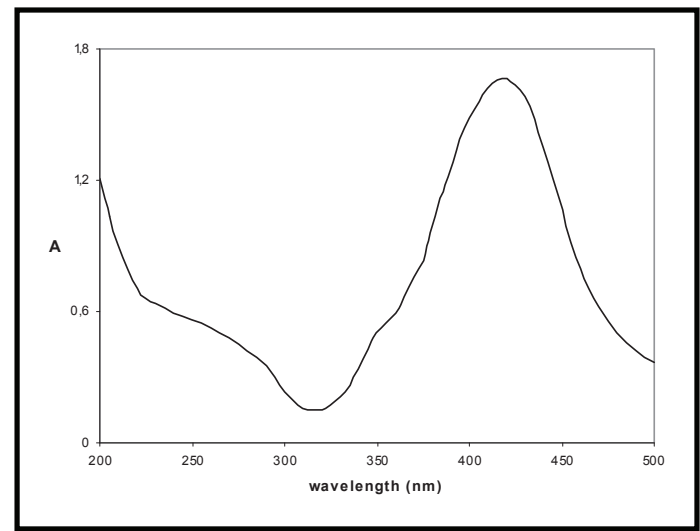

Fig. 8. Absorption spectrum of synthesized AgNPs-EDTA ( $\left.\lambda_{\max }=415 \mathrm{~nm}\right)$.

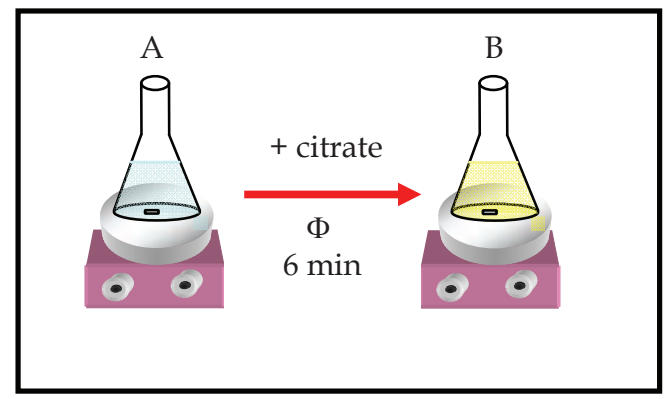

Fig. 9. Synthesis of AgNPs by citrate reduction.

A: $\mathrm{AgNO}_{3}$ solution (colorless); B: AgNPs obtention (yellow).

The chelating reagent EDTA has been used as derivatizing agent for obtaining stable nanoparticles (b-Pan et al., 2007). This coater suffers a chemisorption process onto the surface of AgNPs through carboxylate groups, which are coordinated symmetrically to the Ag atoms. The surface of AgNPs remains negatively charged and, in presence of counter ions, acquires an electrostatic double layer, that it provides a repulsive force enabling to silver colloid to be stable in aqueous solution (Creighton et al., 1979; Heard et al., 1983; Vickova et al., 1996).

Considering that the possibility of using EDTA-AgNPs with analytical purposes depends on obtaining nanomaterial of high pure grade, it was necessary to add a purification step to eliminate all excess of reactant. Concentrated $\mathrm{NaOH}$ aqueous solution was added to EDTAAgNPs solution and, after 15 min of reacting time, the flocculation process took place (He et al., 2004). It was observed that the solution color changed immediately from yellow to violet. The dramatical diminution of $\mathrm{Z}$ potential led to form the big flaks of nanoparticles, which facilitated the phase's separation by flocculation (Fig. 10). 
This phenomenon is reversible once the hydroxide is removed by subsequent wash steps, obtaining a transparent solution of monodispersed nanoparticles (Fig. 11) with average size of $40 \mathrm{~nm}$ (Fig. 12A, B and C).

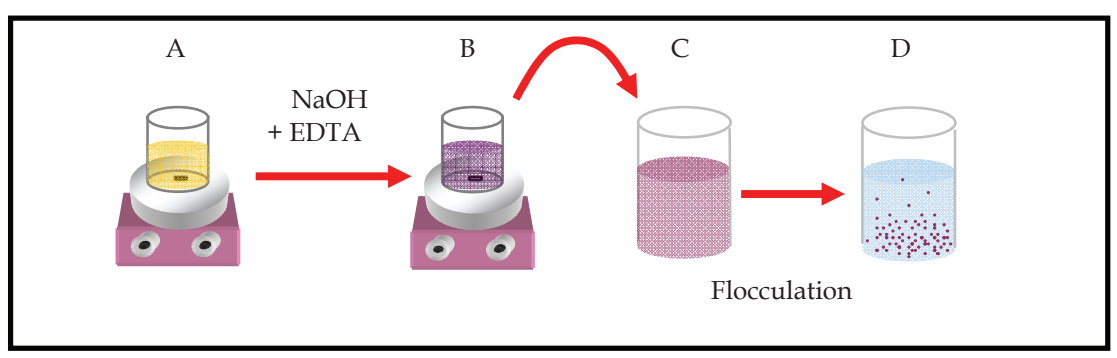

Fig. 10. Derivatization of AgNPs and flocculation process.

A: Recently synthesized AgNPs solution; B: Capped EDTA reaction; C: EDTA-AgNPs product; D: Spontaneous flocculation of EDTA-AgNPs.

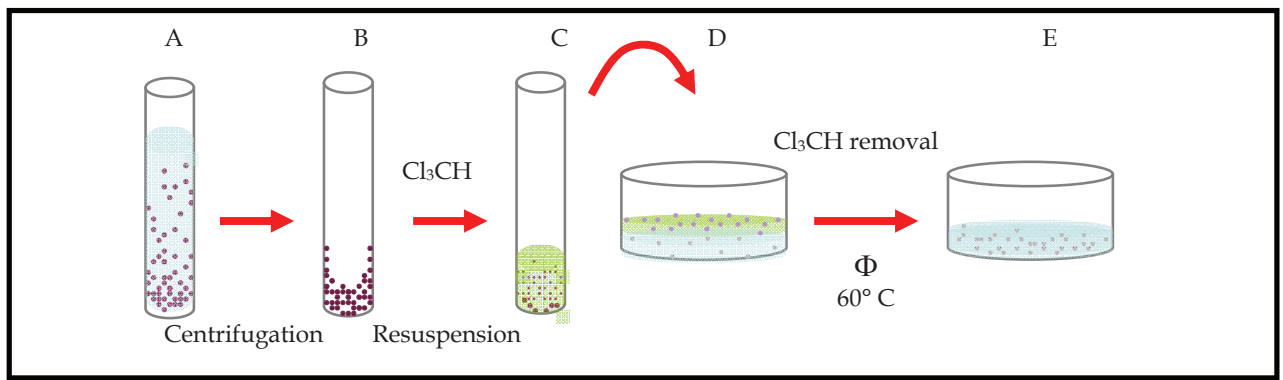

Fig. 11. EDTA-AgNPs purification process.

A: EDTA-AgNPs floccules; B: Solvent remotion; C: EDTA-AgNPs chloroform suspension; D: Chloroform remotion process; E: EDTA-AgNPs monodisperse solution.

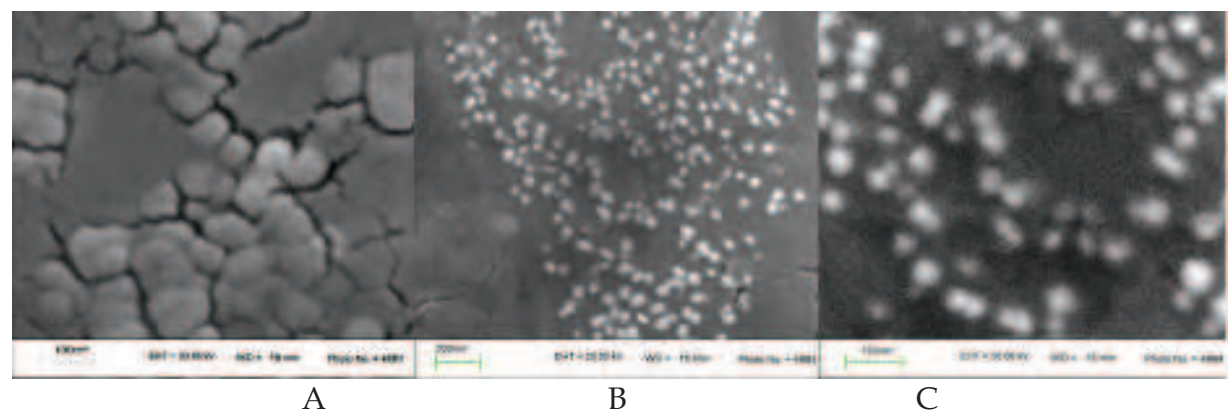

Fig. 12. SEM images of AgNPs. A: Before derivatization step. B and C: After EDTA derivatization step.

There exist a wide variety of substances which act as quenchers of fluorescence as well as different types of quenching process. Nitrate is considered an electron deficient. This kind of 
quencher probably involves donation of electrons from the surface of nanoparticles to the quencher, deactiving the excitate state responsible of fluorescence (Lakowicz, 1999). It is well known that fluorescent emission and SOS are associated phenomena; consequently the fluorescence quenching of EDTA-AgNPs by nitrates affects directly to its SOS signals.

In order to determine the quenching type, a study of the $\mathrm{K}_{\mathrm{sv}}$ (Stern-Volmer constant) from the modified Stern-Volmer equation (Eqs. (1) and (2)) was carried out at different temperature.

$$
\mathrm{F}_{\mathrm{o}} / \mathrm{F}=1+\mathrm{K}_{\mathrm{sv}} \mathrm{C}_{\mathrm{q}}
$$

Stern-Volmer equation for fluorescent quenching, where $\mathrm{F}_{\mathrm{o}}$ and $\mathrm{F}$ are fluorescent emissions of the fluorophore in absence and presence of the quencher respectively; $\mathrm{K}_{\mathrm{sv}}$ is the SternVolmer constant; and $\mathrm{C}_{\mathrm{q}}$ is the concentration of the quencher.

Replacing the term Fo/F by Io/I:

$$
\mathrm{I}_{\mathrm{o}} / \mathrm{I}=1+\mathrm{K}_{\mathrm{sv}} \mathrm{C}_{\mathrm{q}}
$$

modified Stern-Volmer equation for SOS decrease; where $\mathrm{I}_{\mathrm{o}}$ and I are SOS intensities of EDTA-AgNPs in absence and presence of nitrates, respectively.

Table 3 shows the obtained $\mathrm{K}_{\mathrm{sv}}$ values. The linearity of the Stern-Volmer plot, as the value of $\mathrm{K}_{\mathrm{sv}}$, which enhanced with increasing temperature (Fig. 13), indicated that the quenching mechanism of Ag-EDTA NPs by presence of nitrate is a single dynamic quenching (Lakowicz, 1999).

When the time of AgNPs synthesis process is extended, a larger size of nanoparticles is obtained and in the fluorescence spectrum, the huge dispersion of the light produces an increase of the noise. After derivatization, the noise of fluorescent spectrum was minimized; nevertheless, the decreasing of SOS and fluorescence quenching for

these nanoparticles in presence of nitrate was not efficient. This phenomenon may be due to the superficial activity diminution produced by the increase

of the particles size; simultaneously, it is reduced the capability of nitrate to produce the deactivation process of the excited state. 


\begin{tabular}{cl}
\hline $\begin{array}{l}\text { Temperature } \\
(\mathrm{K})\end{array}$ & $\begin{array}{l}\mathrm{K}_{\mathrm{sv}} \text { value } \\
\left(\mu \mathrm{g} \mathrm{mL}^{-1}\right)\end{array}$ \\
\hline 293 & 0.736 \\
303 & 0.991 \\
313 & 1.213 \\
323 & 1.456 \\
\hline
\end{tabular}

Table 3. $\mathrm{K}_{\mathrm{sv}}$ values for different experimental temperatures.

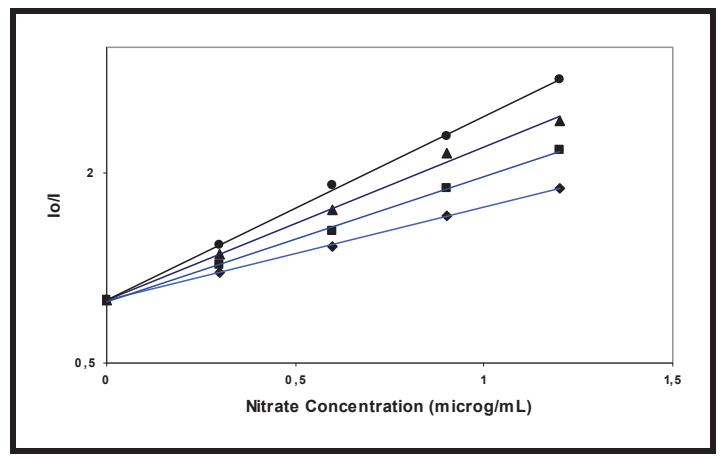

Fig. 13. Influence of temperature on AgNPs-EDTA SOS signals in presence of nitrate.

$\left[\mathrm{NO}_{3}^{-}\right.$]: $0.00 ; 0.30 ; 0.60 ; 0.90 ; 1.20 \mu \mathrm{g} \mathrm{mL}-1$. Instrument conditions: $\lambda_{\mathrm{ex}}=225 \mathrm{~nm} ; \lambda \mathrm{em}=450 \mathrm{~nm}$.

Under the optimal experimental conditions, calibration curves for the determination of nitrate by SOS and fluorescence were obtained. By SOS decrease, the results showed a good linear relationship over the range $6.410^{-4}$ to $3.0 \mu \mathrm{g} \mathrm{mL}^{-1}$. The linear regression equation was $\Delta \mathrm{I}_{\text {sos }}=228.50 \mathrm{C}\left(\mu \mathrm{g} \mathrm{mL}^{-1}\right)+0.84$ with regression coefficient $\mathrm{r}=0.997$. The LOD estimated was $1.810^{-4} \mu \mathrm{g} \mathrm{mL}^{-1}$; while for quenching of fluorescence emission the equation of calibration curve was $\Delta \mathrm{F}=34.40 \mathrm{C}\left(\mu \mathrm{g} \mathrm{mL} \mathrm{L}^{-1}\right)+1$, value means lost of sensitivity compared with SOS technique.

The obtained results showed that the EDTA-AgNPs can be applied as sensor for nitrate (Table 4).

\begin{tabular}{ccccc}
\hline Samples & Base value & $\begin{array}{c}\text { Added } \\
\left(\mu \mathrm{g} \mathrm{mL}^{-1}\right)\end{array}$ & $\begin{array}{c}\text { Found } \\
\left(\mu \mathrm{g} \mathrm{mL}^{-1}\right)\end{array}$ & $\begin{array}{c}\text { Recovery } \\
\text { RSD }^{\mathrm{c}}(\%)\end{array}$ \\
\hline $\mathrm{A}$ & -- & 0.000 & 0.006 & -- \\
& 0.006 & 0.250 & 0.252 & $98.43 \pm 1.89$ \\
& 0.006 & 0.500 & 0.503 & $99.40 \pm 1.77$ \\
& 0.006 & 0.750 & 0.768 & $101.50 \pm 2.21$ \\
\hline B & -- & 0.000 & 0.009 & -- \\
& 0.009 & 0.250 & 0.263 & $101.54 \pm 1.45$ \\
& 0.009 & 0.500 & 0.507 & $99.60 \pm 2.10$ \\
& 0.009 & 0.750 & 0.749 & $98.68 \pm 1.87$ \\
\hline
\end{tabular}

Table 4. Nitrate determination in parenteral solutions. Recovery studya.

a AgNPs-EDTA systems prepared and measured as described in general procedure.

${ }^{b}$ Recovery $=100 \times[($ found-base $) /$ added $] .{ }^{c}(n=6)$. 
The effect of AgNPs on the fluorescence and SOS intensity of Tb(III) - ciprofloxacin (CPLX) complex in aqueous solution has been reported (Zhao et al., 2008) and a new method was developed to determine the concentration of CPLX by the SOS and fluorescence intensity of the system, which expands the field of analytical application of AgNPs.

To a $10 \mathrm{~mL}$ calibrated tube were added in the order of $2 \mathrm{~mL}$ of HAc-NaAc buffer solution, $\mathrm{Tb}(\mathrm{III})$ ion solution, CPLX, and AgNPs. And the mixture was diluted to $10 \mathrm{~mL}$ with doubly distilled water, shaken thoroughly, and left to stand for $30 \mathrm{~min}$. In order to choose the optimal excitation and emission wavelengths, the different exciting wavelengths from 220 to $350 \mathrm{~nm}$ were used to record the signal peaking at $440-700 \mathrm{~nm}\left(\lambda_{\text {SOS }}=2 \lambda_{\mathrm{ex}}\right)$, correspondingly. The intensity reached the maximum at $545 \mathrm{~nm}$ with $\lambda_{\mathrm{ex}}=272 \mathrm{~nm}$. All data were obtained by using the slit-width of excitation and emission of the spectrofluorometer at $5 \mathrm{~nm}$. The relative intensities of fluorescence and SOS $\Delta \mathrm{I}$ (the difference between the intensity of CPLX solution and that of the blank solution without CPLX) were proportional to the concentration of CPLX.

Under the optimum condition defined, the calibration graphs for CPLX were obtained. The relative standard deviation was $1.6 \%$ for nine determinations of $1.010^{-6} \mathrm{~mol} \mathrm{~L}^{-1}$ CPLX. The linear range of the calibration graph is from $3.010^{-9}$ to $1.010^{-5} \mathrm{~mol} \mathrm{~L}^{-1}$, and the detection limit calculated from the standard deviation of the blank (the reagent blank without CPLX, $\mathrm{n}=19)(3 \sigma)$ is $8.510^{-10} \mathrm{~mol} \mathrm{~L}^{-1}$.

The proposed method was applied to the determination of CPLX in capsules and tablets, and compared with UV-vis method without significant difference between the labeled content and that obtained by this method.

\section{Conclusions}

In this chapter, some representative researchs based on the application of AgNPs to chemical and biological sensors using absorption, emission and scattering phenomena, have been commented. The inusual optical properties mainly related to their high extinction coefficient and tunable particle shapes, have turned to AgNPs in a very attractive and special usefull analytical tool: their have been applied to trace determination of different nature analytes with sucessfully results.

Due to its high efficiency and low cost, the light scattering techniques based on AgNPs shows particular promise in the development of noninvasive in vivo sensing techniques for the study of biological systems, particular to immunoassays and to monitoring the interaction between proteins and enzymes in living cells. Light-scattering signals could have widespread applications in detection and quality control of new developed nanodrugs.

AgNPs have a promising future in designing of optical sensors. Their utilization will be driven by the need for smaller detection devices with lower limits of detection. Continual advances in nanofabrication technology and optical characterization techniques are expected to overcome the difficulties encountered in the development of TERS. One major challenge is improve the collection and detection efficiency of the traditional SERS instrumentation. Another challenge is the fabrication of an optical probe that incorporates a SERS substrate. The modification of fiber-optic probes with metal films or nanoparticles provides a promising solution, but great care must be taken to ensure long-term stability of the metal substrate and to permit reuse of the probe. 
The success of new applications of AgNPs depends on improvement in the understanding of the properties of SPR. Further efforts and systematic study must be assumed in order to offer new developments to extend the analytical applications field of AgNPs.

\section{References}

Balan, L.; Malval, J.; Schneider, R. \& Burget, D. (2007). Silver nanoparticles: New synthesis, characterization and photophysical properties. Mat. Chem. Phys., 104, 2-3, (August 2007), 417-421, ISSN 0254-0584.

Bhandari, D.; Wells, S.; Retterer, S. \& Sepaniak, M. (2009). Characterization and detection of uranyl ion sorption on silver surfaces using surface enhanced Raman spectroscopy. Anal. Chem., DOI: 10.1021/ac901266f, ISSN 0003-2700.

Bruzzone, S.; Malvaldi, M.; Arrighini, G. \& Guidotti C. (2005). Theoretical study of electromagnetic scattering by metal nanoparticles. J. Phys. Chem. B, 109, (February 2005), 3807- 3812, ISSN 0022-3654.

Campion, A. \& Kambhampati, P. (1998). Surface-enhanced Raman scattering. Chem. Soc. Rev., 27, (February 1998), 241-250, ISSN 0306-0012.

Cao, Y.; Jin, R. \& Mirkin, C. (2002) Nanoparticles with Raman spectroscopic fingerprints for DNA and RNA detection. Science, 297, (August 2002), 1536-1540, ISSN 0036-8075.

Cognet, L.; Tardin, C.; Boyer, D.; Choquet, D.; Tamarat, P. \& Lounis, B. (2003). Single metallic nanoparticle imaging for protein detection in cells. Proc. Natl. Acad. Sci. U.S.A., 100, 20, (September 2003), 11350-11355, ISSN 0027-8424.

Creighton, J.; Blatchford, C. \& Albrecht, M. (1979). Plasma resonance enhancement of Raman scattering by pyridine adsorbed on silver or gold sol particles of size comparable to the excitation wavelength. J. Chem. Soc. Faraday Trans. 2, 75, 790-798, ISSN 03009238. DOI: 10.1039/F29797500790.

Daniels, J.; Caldwell, T.; Christensen, K. \& Chumanov, G. (2006). Monitoring the kinetics of Bacillus subtilis endospore germination via surface-enhanced Raman scattering. Anal. Chem., 78, 5, (Febrary 2006), 1724-1729, ISSN 0003-2700.

Ding, F.; Zhao, H.; Jin, L. \& Zheng, D. (2006). Study of the influence of silver nanoparticles on the second-order scattering and the fluorescence of the complexes of $\mathrm{Tb}(\mathrm{III})$ with quinolones and determination of the quinolones. Anal. Chim. Acta, 566, 1 (April 2006) 136-143, ISSN 0003-2670.

Docherty, F.; Clark, M.; McNay, G.; Graham, D. \& Smith, W. (2004). Multiple labelled nanoparticles for bio detection. Faraday Discuss., 126, (October 2003), 281-288, ISSN 1364-5498.

a) Dubas, S. \& Pimpan, V. (2008). Green synthesis of silver nanoparticles for ammonia sensing. Talanta, 76, (June 2008), 29-33. ISSN 0039-9140.

b) Dubas, S. \& Pimpan, V. (2008). Humic acid assisted synthesis of silver nanoparticles and its application to herbicide detection. Mater. Lett., 62, (June 2008), 2661-2663, ISSN 0167-577X.

El-Sayed, I.; Huang, X. \& El-Sayed, M. (2005). Surface plasmon resonance scattering and absorption of anti-EGFR antibody conjugated gold nanoparticles in cancer diagnostics: applications in oral cancer. Nano Lett., 5, 5, (May 2005), 829-834, ISSN 1530-6984. 
Esumi, K.; Tano, T.; Torigae, K. \& Meguro K. (1990). Preparation and characterization of bimetallic palladium-copper colloids by thermal decomposition of their acetate compounds in organic solvents. Chem. Mater., 5, (September 1990) 564-567, ISSN 0897-4756.

Faraday, M. (1857). The Bakerian lecture: experimental relations of gold (and other metals) to light. Phil. Trans. R. Soc. Lond. , 147 (January 1857) 145-181, ISSN 0261-0523.

Goldys, E. \& Xie, F. (2008). Metallic nanomaterials for sensitivity enhancement of fluorescence detection. Sensors, 8, (February 2008), 886-896, ISSN 1424-8220.

Gole, A. \& Murphy, C. (2004). Seed-mediated synthesis of gold nanorods: role of size and nature of the seed. Chem. Mater., 16, 19, (August 2004), 3633-3640, ISSN 0897-4756.

Goulet, P.; Pieczonka, N. \& Aroca, R. (2003). Electrokinetic focusing injection methods on microfluidic devices. Anal. Chem., 75, 8, (March 2003), 1918-1923, ISSN 0003-2700.

Guerrini, L.; Aliaga, A.; Cárcamo, J.; Gómez-Jeria, J.; Sanchez-Cortes, S.; Campos-Vallette, M. \& García-Ramos, J. (2008). Functionalization of Ag nanoparticles with the bisacridinium lucigenin as a chemical assembler in the detection of persistent organic pollutants by surface-enhanced Raman scattering. Anal. Chim. Acta, 624, 2, (August 2008), 286-293, ISSN 0003-2670.

Haes, A.; Zou, S.; Schatz, G. \& Van Duyne, R. (2004). Nanoscale optical biosensor: short range distance dependence of the localized surface plasmon resonance of noble metal nanoparticles. J. Phys. Chem. B, 108, ( March 2004), 6961-6968 ISSN 0022-3654.

a) Han, C; Zhang, L. \& Li, H. (2009). Highly selective and sensitive colorimetric probes for $\mathrm{Yb}\left({ }^{3+}\right)$ ions based on supramolecular aggregates assembled from beta-cyclodextrin4,4'-dipyridine inclusion complex modified silver nanoparticles. Chem. Commun., 24, (June 2009), 3545-3547, ISSN 1359-7345.

b) Han, X.; Cai, L..; Guo, J.; Wang, C.; Ruan W.; Han, W.; Xu, W.; Zhao, B. \& Ozaki, Y. (2008). Fluorescein Isothiocyanate linked immunoabsorbent assay based on surfaceenhanced Raman scattering. Anal. Chem., 80, 8, (March 2008), 3020-3024, ISSN 00032700.

c) Han, X.; Huang, G. ; Zhao B.; \& Ozaki, Y. (2009). Label-free highly sensitive detection of proteins in aqueous solutions using surface-enhanced Raman scattering. Anal. Chem., 81, 9, (March 2009), 3329-3333, ISSN 0003-2700.

d) Han, X.; Jia, H.; Wang, Y.; Lu, Z.; Wang, C.; Xu, W.; Zhao, B. \& Ozaki, Y. (2008). Analytical technique for label-free multi-protein detection based on Western Blot and surface-enhanced Raman scattering. Anal. Chem., 80, 8, (February 2008), 27992804, ISSN 0003-2700.

Haynes, C. \& Van Duyne, R. (2001) Nanosphere lithography: a versatile nanofabrication tool for studies of size-dependent nanoparticle optics. J. Phys. Chem. B, 105, (June 2001), 5599-5611, ISSN 1089-5647.

He, B.; Tan, J.; Liew, K. \& Liu, H. (2004). Synthesis of size controlled Ag nanoparticles. J. Mol. Catal. A Chem., 221, 1-2 (November 2004) 121-126, ISSN 1381-1169.

Heard, S.; Grieser, F. \& Barraclough, C. (1983). The characterization of Ag sols by electron microscopy, optical absorption, and electrophoresis. J. Colloid Interface Sci. 93, 2 (June 1983) 545-555, ISSN 0021-9797.

Henglein, A. \& Giersig, M._(1999). Formation of colloidal silver nanoparticles: capping action of citrate. J. Phys. Chem. B., 103, 44, (November 1999), 9533-9539, ISSN 15206106. 
Hildebrandt, P. \& Stockburger, M. (1984). Surface-enhanced resonance Raman spectroscopy of Rhodamine 6G adsorbed on colloidal silver. J. Phys. Chem., 88, (November 1984), 5935-5944, ISSN 0022-3654

Hirsch, L.; Stafford, R.; Bankson, J.; Sershen, S.; Rivera, B.; Price, R.; Hazle, J.; Halas, N. \& West, J. (2003). Nanoshell-mediated near-infrared thermal therapy of tumors under magnetic resonance guidance. Proc. Natl. Acad. Sci. U.S.A., 100, 23, (November 2003), 13549-13554, ISSN 0027-8424.

Huang, G.; Han, X.; Hossain, M. \& Ozaki, Y. (2009). Development of a heat-induced surfaceenhanced Raman scattering sensing method for rapid detection of glutathione in aqueous solutions. Anal. Chem., 81, 14, (June 2009), 5881-5888, ISSN 0003-2700.

Ivleva, N.; Wagner, M.; Horn, H.; Niessner, R. \& Haisch, C. (2008). In situ surface-enhanced Raman scattering analysis of biofilm. Anal. Chem, 80, 22, (October 2008), 8538-8544, ISSN 0003-2700.

Jeanmaire, D. \& Van Duyne, R. (1977). Surface Raman spectroelectrochemistry: Part I. Heterocyclic, aromatic, and aliphatic amines adsorbed on the anodized silver electrode. J. Electroanal. Chem., 84, (November 1977), 1-20, ISSN 0022-0728.

a) Jiang, J.; Bosnick, K.; Maillard, M. \& Brus, L. (2003). Single molecule Raman spectroscopy at the junctions of large Ag nanocrystalsJ. Phys. Chem. B, 107, (September 2003), 9964-9972, ISSN 1089-5647.

b) Jiang, Z.; Yuan, W. \& Pan, H. (2005). Luminescence effect of silver nanoparticle in water phase. Spectrochim. Acta Part A, 61, 11-12 (September 2005) 2488-2494, ISSN 13861425.

Kelly, K.; Coronado, E.; Zhao, L. \& Schatz, G. (2004). The optical properties of metal nanoparticles: the influence of size, shape, and dielectric environment. J. Phys. Chem. B, 107, 3, (December 2002), 668-677, ISSN 1089-5647.

a) Kneipp, H.; Kneipp, J. \& Kneipp, K. (2006). Surface-enhanced Raman Optical Activity on Adenine in Silver Colloidal Solution. Anal. Chem., 78, 4, (January 2006), 1363-1366, ISSN 0003-2700.

b) Kneipp, K.; Kneipp, H.; Itzkan, I.; Dasari, R. \& Feld, M. (1999). Ultrasensitive chemical analysis by Raman spectroscopy. Chem. Rev., 99, (September 1999), 2957-2975, ISSN 0009-2665.

c) Kneipp, K.; Kneipp, H.; Kartha, V.; Manoharan, R.; Deinum, G.; Itzkan, I.; Dasari, R. \& Feld, M. (1998). Detection and identification of a single DNA base molecule using surface-enhanced Raman scattering (SERS). Phys. Rev. E, 57, 6, (June 1998), R6281R6284, ISSN 1063-651X.

d) Kneipp, K.; Wang, Y.; Kneipp, H.; Perelman, L.; Itzkan, I.; Dasari, R. \& Feld, M. (1997). Single Molecule Detection Using Surface-Enhanced Raman Scattering (SERS). Phys. Rev. Lett., 78, (March 1997), 1667-1670, ISSN 0031-9007.

Lakowicz, J. (1999). Principles of fluorescence spectroscopy, 2nd Ed., 239-240, Plenum Press, ISBN-10: 0306460939. ISBN-13: 978-0306460937, New York.

a) Li, H. E Bian, Y. (2009). Selective colorimetric sensing of histidine in aqueous solutions using cysteine modified silver nanoparticles in the presence of $\mathrm{Hg}^{2+}$. Nanotechnol., 20, (April 2009), 145502 (6pp), ISSN 0957-4484. 
b) Li, N.; Liu, S. \& Luo, H. (2002). Frequency doubling scattering and second-order scattering technology as novel methods for the determination of the inclusion constant of procaine hydrochloride to $\beta$-cyclodextrin. a) Anal. Chim. Acta, 472, 1-2 (November 2002) 89-98, ISSN 0003-2670.

a) Ling, J.; Huang, C.; Li, Y.; Zhang, L.; Chen, L. \& Zhen, S. (2009). Light-scattering signals from nanoparticles in biochemical assay, pharmaceutical analysis and biological imaging. Trends in Anal. Chem., 28, (April 2009), 447-453, ISSN 0167-2940.

b) Ling, J.; Sang, Y. \& Huang, C. (2008). Visual colorimetric detection of berberine hydrochloride with silver nanoparticles. J. Pharmaceut. Biomed. Anal., 47, (August 2008), 860-864, ISSN 0731-7085.

a) Liu, C.; Li, Z.; Du, B.; Duan, X.\& Wang, Y. (2006). Silver nanoparticle-based ultrasensitive chemiluminescent detection of DNA hybridization and singlenucleotide polymorphisms. Anal. Chem., 78, (June 2006), 3738-3744 , ISSN 00032700.

b) Liu, C.; Yang, X.; Yuan, H.; Zhou, Z. \& Xiao, D. (2007) Preparation of silver nanoparticle and its application to the determination of ct-DNA. Sensors, 7, (May 2007), 708-718, ISSN 1424-8220.

Liz-Marzan, L. \& Philipse, A. (1995). Stable hydrosols of metallic and bimetallic nanoparticles immobilized on imogolite fibers. J. Phys. Chem., 99, (October 1995) 15120-15128, ISSN 0022-3654.

Luo, Y. \& Sun, X. (2007). Rapid, single-step preparation of dendrimer-protected silver nanoparticles through a microwave-based thermal process. Mater. Lett., 61, 8-9, (April 2007), 1622-1624, ISSN 0167-577X.

MacAskill, A.; Crawford, D.; Graham, D. \& Faulds, K. (2009). DNA sequence detection using surface-enhanced resonance Raman spectroscopy in a homogeneous multiplexed assay. Anal. Chem., DOI: 10.1021/ac901361b, ISSN 0003-2700.

Mafuné, F.; Kohnok, J.; Takeda, Y. \& Kondow, T. (2000). Structure and stability of silver nanoparticles in aqueous solution produced by Laser ablation. J. Phys. Chem. B., 104, 35, (August 2000) 8333-8337, ISSN 1520-6106.

Mc Farland, A. \& Van Duyne, R. (2003). Single silver nanoparticles as real-time optical sensors with zeptomole sensitivity. Nano Lett., 3, 8, (August 2003), 1057-1062, ISSN 1530-6984.

Michaels, A.; Jiang, J. \& Brus, L. (2000). Ag nanocrystal junctions as the site for surfaceenhanced Raman scattering of single Rhodamine 6G molecules. J. Phys. Chem. B, 104, (December 2000), 11965-11971, ISSN 1089-5647.

Mie, G. (1908). Beiträge zur Optik trüber Medien speziell kolloidaler Goldlösungen (contributions to the optics of diffuse media, especially colloidal metal solutions). Ann. Phys., 25, (March 1907), 377-445, ISSN 0003-3804.

Mock, J.; Barbic, M.; Smith, D.; Schultz, D. \& Schultz, S. (2002). Shape effects in plasmon resonance of individual colloidal silver nanoparticles. J. Chem. Phys., 116., 15, (April 2002), 6755-6759, ISSN 0021-9606.

Monaghan, P.; McCarney, K.; Ricketts, A.; Littleford, R.; Docherty, F.; Smith, E.; Graham, D. \& Cooper, J. (2007). Bead-based DNA diagnostic assay for Chlamydia using nanoparticle-mediated surface-enhanced resonance Raman scattering detection within a lab-on-a-chip format. Anal. Chem., 79, 7, (February 2007), 2844-2849, ISSN 0003-2700. 
Moskovits, M. (1985). Surface-enhanced spectroscopy. Rev. Mod. Phys., 57, 3, (July 1985), 783-826, ISSN 00346861.

Mrozek, M. \& Weaver, M. (2002). Detection and identification of aqueous saccharides by using surface-enhanced Raman spectroscopy. Anal. Chem., 74, 16, (June 2002), 40694075, ISSN 0003-2700.

Nie, S.; Emory, S. R. (1997). Probing single molecules and single nanoparticles by surfaceenhanced Raman scattering. Science, 275, (February 1997), 1102-1106, ISSN 00368075 .

a) Olenin, A.; Romanovskaya, G.; Krutyakov, Y.; Lisichkin, G. \& Zuev, V. (2008). Sensitized fluorescence of silver nanoparticles in the presence of Pyrene. Doklady Chem. (April 2008), 419, 91-94, ISSN 0012-5008.

b) Olenin, A.; Romanovskaya, G.; Krutyakov, Y.; Vasil'eva, S.; Kudrinskii, A. \& Lisichkin, G. (2009). Synthesis and adsorption and luminescence properties of hydrophobic silver nanoparticles in the presence of pyrene. J. Anal. Chem., 64, (January 2009), 2630, ISSN 1061-9348.

Otto, A. (1984). Electronic scattering, spin effects, SERS and morphic effects, In: Light scattering in solids IV, Cardona, M., \& Guntherodt, G., (Ed.), 289-418, SpringerVerlag:, ISBN 3540119426, Berlin, Germany.

Pal, A. \& Maji, S. (2005). Arsine-induced formation of silver nanoparticles in micellar medium. application to spectrophotometric determination of arsenic. Chem. Anal. (Warsaw), 50, 6, (November - December 2005), 1077- 1086, ISSN 0009-2223.

a) Pan, H.; Liang, F.; Mao, C. \& Zhu, J. (2007). Sonochemical synthesis and resonance light scattering effect of Zn(II)bis(1-(2-pyridylazo)-2-naphthol) nanorods. Nanotechnol., 18, (May 2007), 195606, ISSN 0957-4484.

b) Pan, H.; Tao, X.; Mao, C.; Zhu, J. \& Liang, F. (2007). Aminopolycarboxyl-modified $\mathrm{Ag}_{2} \mathrm{~S}$ nanoparticles: Synthesis, characterization and resonance light scattering sensing for bovine serum albumin. Talanta, 71, 1 (January 2007) 276-281, ISSN 0039-9140.

Park, H.; Alam, S.; Lee, S.; Karim, M.; Wabaidur, S.; Kang, M. \& Choi, J. (2009). Optical ascorbic acid sensor based on the fluorescence quenching of silver nanoparticles. Luminescence, DOI: 10.1002/bio.1160.

Pastoriza-Santos, I. \& Liz-Marzan, L. (2002). Formation of PVP-protected metal nanoparticles in DMF. Langmuir, 18, 7, (February 2002) 2888-2894, ISSN 0743-7463.

Petit, C.; Lixon, P. \& Pileni, M. (1993). Synthesis in situ of silver nanocluster in AOT reverse micelles. J. Phys. Chem., 97, 49 (December 1993) 12974-12983, ISSN 0022-3654.

Pettinger, B.; Picardi, G.; Schuster, R. \& Ertl, G. (2002). Surface-enhanced and STM-tipenhanced Raman spectroscopy at metal surfaces. Single Mol., 3, 5-6 (November 2002), 285-294, ISSN 1438-5163.

Pyatenko, A.; Yamaguchi, M. \& Suzuki, M. (2005). Laser photolysis of silver colloid prepared by citric acid reduction method. J. Phys. Chem. B, 109, 46, (November 2005) 21608-21611, ISSN 1520-6106.

a) Rao, C.; Kulkarni, G.; Thomas, P. \& Edwards, P. (2000). Metal nanoparticles and their assemblies. Chem. Soc. Rev., 29, (January 2000) 27- 35, ISSN 0306-0012.

b) Rao, C.; Kulkarni, G.; Thomas, P. \& Edwards, P. (2002). Size-Dependent Chemistry: Properties of Nanocrystals, Chem. Eur. J., 8, 1, (December 2001), 28-35, ISSN 09476539. 
a) Rayleigh, J. (1871). On the light from the sky, its polarisation and colour. I. Phil. Mag., 41, (April 1871), 107-120, ISSN 1364-2812.

b) Rayleigh, J. (1871). On the light from the sky, its polarisation and colour. II. Phil. Mag., 41, (April 1871), 274-27, ISSN 1364-2812.

Richards, D.; Milner, R.; Huang, F. \& Festy, F. (2003) Tip-enhanced Raman microscopy: practicalities and limitations. J. Raman Spectrosc., 34, (September 2003), 663-667, ISSN

Rivas, L.; Sanchez-Cortes, S.; Garcia-Ramos, J. \& Morcillo, G. (2001). Growth of silver colloidal particles obtained by citrate reduction to increase the Raman enhancement factor. Langmuir, 17, (January 2001) 574-577, ISSN 0743-7463.

Roll, D.; Malicka, J.; Gryczynski, I.; Gryczynski, Z. \& Lakowicz, J. (2003). Metallic colloid wavelength-ratiometric scattering sensors. Anal. Chem., 75, 14, (July 2003), 34403445, ISSN 0003-2700.

Schatz, G. \& Van Duyne, R. (2002). Vol. 1. In Handbook of vibrational spectroscopy, Chalmers, J. \& Griffiths, P., (Ed.), 759-774, John Wiley \& Sons, ISBN 978-0-471-98847-2, New York.

Schultz, S.; Smith, D.; Mock, J. \& Schultz, D. (2000). Single-target molecule detection with nonbleaching multicolor optical immunolabels. Proc. Natl. Acad. Sci. U.S.A., 97, 3, (February 2000), 996-1001, ISSN 0027-8424.

Shang, L.; Qin, C.; Jin, L.; Wang, L. \& Dong, S. (2009). Turn-on fluorescent detection of cyanide based on the inner filter effect of silver nanoparticles. Analyst, 134, 7, (July 2009), 1477-1482, ISSN 0003-2654.

Sosa, I. \& Noguez, C. (2003). Optical properties of metal nanoparticles with arbitrary shape. J. Phys. Chem.B, 107, (June 2003), 6269-6275, ISSN 1089-5647.

Stosch, R.; Henrion, A.; Schiel, D. \& Güttler, B. (2005). Surface-enhanced Raman scattering based approach for quantitative determination of creatinine in human serum. Anal. Chem., 77, 22, (October 2005), 7386-7392, ISSN 0003-2700.

Talley, C.; Jusinski, L.; Hollars, C.; Lane, S. \& Huser, T. (2004). Intracellular pH sensors based on surface-enhanced Raman scattering. Anal. Chem., 76, 23, (October 2004), 7064-7068, ISSN 0003-2700.

Taton, T.; Mirkin, C. \& Letsinger, R. (2000). Scanometric DNA array detection with nanoparticle probes. Science, 289, 5485, (September 2000), 1757-1760, ISSN 00368075 .

Thompson, D.; Enright, A.; Faulds, K.; Smith, W. \& Graham, D. (2008). Ultrasensitive DNA detection using oligonucleotide-silver nanoparticle conjugates. Anal. Chem., 80, (April 2008), 2805-2810, ISSN 0003-2700.

Toshima, N.; Yonezawa, T. \& Kushihashi K. (1993). Polymer-protected palladium-platinum bimetallic clusters: preparation, catalytic properties and structural considerations. J. Chem. Soc. Faraday Trans., 89, 14, (July 1993) 2537-2543, ISSN 0956-5000.

Van Dijk, M.; Tchebotareva, A.; Orrit, M.; Lippitz, M.; Berciaud, S.; Lasne, D.; Cognet, L. \& Lounis, B. (2006). Absorption and scattering microscopy of single metal nanoparticles. Phys. Chem. Chem. Phys., 8, (August 2006), 3486-3495, ISSN 1463-9076.

Vickova, B.; Tsai, D.; Gu, X. \& Moskovits M. (1996). A microscopic surface-enhanced raman study of a single adsorbate-covered colloidal silver aggregate. J. Phys. Chem., 100, 8 (February1996) 3169-3174, ISSN 0022-3654. 
Wabuyele, M. \& Vo-Dinh, T. (2005). Detection of human immunodeficiency virus type 1 DNA sequence using plasmonics nanoprobes. Anal. Chem., 77, 23, (October 2005), 7810-7815, ISSN 0003-2700.

Wang, C.; Luconi, M.; Masi, A. \& Fernández, L. (2009). Derivatized silver nanoparticles as sensor for ultra-trace nitrate determination based on light scattering phenomenon. Talanta, 77, 3 (January 2009) 1238-1243. 0039-9140.

Wei, H.; Chen, C.; Han, B. \& Wang, E. (2008). Enzyme colorimetric assay using unmodified silver nanoparticles. Anal. Chem, 80, (September 2008), 7051-7055, ISSN 0003-2700.

Wilson, R.; Monaghan, P.; Bowden, S.; Parnell, J. \& Copper, J. (2007). Surface-enhanced Raman signatures of pigmentation of cyanobacteria from within geological samples in a spectroscopic-microfluidic flow cell. Anal. Chem., 79, 18, (August 2007), 70367041, ISSN 0003-2700.

Woo, M.; Lee, S.; Kim, G.; Baek, J.; Noh, M.; Kim, J.;Park, S.; Tehrani, A.; Park, S.; Seo, Y. Kim, Y.; Lee, Y.; Jeon, D. \& Cho, M. (2009). Multiplex immunoassay using fluorescent-surface enhanced Raman spectroscopy dots for the detection of bronchioalveolar Stem cells in murine lung, Anal. Chem., 81, 3, (December 2009), 1008-1013, ISSN 0003-2700.

Wu, T.; Li, Y. \& Huang, C. (2009). Selectively colorimetric detection of cysteine with triangular silver nanoprisms. Chin. Chem. Lett., 20, (May 2009), 611-614, ISSN 10018417.

Xiong, D. \& Li, H. (2008). Colorimetric detection of pesticides based on calixarene modified silver nanoparticles in water. Nanotechnol., 19, (November 2008), 465502 (6pp), ISSN 0957-4484.

Xiong, X.; Xie, Y.; Du, G.; Liu, X. \& Tian, X. (2002). Ultrasound-assisted self-regulation route to Ag nanorods. Chem. Lett., 102, 1, (January 2002), 98-99, ISSN 0897-4756.

Xu, H.; Bjerneld, E.; Käll, M. \& Börjesson, L. (1999). Spectroscopy of single hemoglobin molecules by surface enhanced Raman scattering. Phys. Rev. Lett., 83, (November 1999), 4357-4360, ISSN 0031-9007.

Yguerabide, J. \& Yguerabide, E. (1998). Light-scattering submicroscopic particles as highly fluorescent analogs and their use as tracer labels in clinical and biological applications: II. Experimental characterization. Anal. Biochem., 262, 2, (September 1998), 157-176. ISSN 0003-2697.

Zhao, H.; Ding, F.; Wang, X.; Ju, H. ; Li, A. \& Jin, L. (2008). A study on silver nanoparticlessensitized fluorescence and second-order scattering of the complexes of $\mathrm{Tb}(\mathrm{III})$ with ciprofloxacin and its applications. Spectrochim. Acta Part A, 70, (July 2008) 332-336, ISSN 1386-1425.

a) Zhou, H.; Wu, X. \& Yang J. (2009). Study on the interaction of nucleic acids with silver nanoparticles-Al(III) by resonance light scattering technique and its analytical application. Talanta, 78, 3, (May 2009) 809-813. 0039-9140.

b) Zhou, Y.; Hao, L.; Hu, Y.; Zhu, Y. \& Chen Z. (2001). Synthesis of nanowires and coralshaped nanostructures of $\mathrm{Ag}$ by an ultraviolet photo-reduction technique at room temperature. Chem. Lett., 30, 11, (November 2001) 1192-1993, ISSN 0366-7022. 


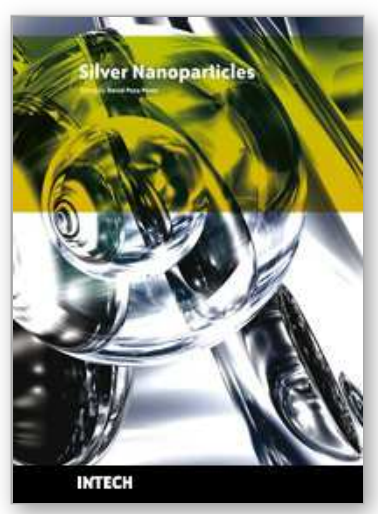

\author{
Silver Nanoparticles \\ Edited by David Pozo Perez
}

ISBN 978-953-307-028-5

Hard cover, 334 pages

Publisher InTech

Published online 01, March, 2010

Published in print edition March, 2010

Nanotechnology will be soon required in most engineering and science curricula. It cannot be questioned that cutting-edge applications based on nanoscience are having a considerable impact in nearly all fields of research, from basic to more problem-solving scientific enterprises. In this sense, books like "Silver Nanoparticles" aim at filling the gaps for comprehensive information to help both newcomers and experts, in a particular fast-growing area of research. Besides, one of the key features of this book is that it could serve both academia and industry. "Silver nanoparticles" is a collection of eighteen chapters written by experts in their respective fields. These reviews are representative of the current research areas within silver nanoparticle nanoscience and nanotechnology.

\title{
How to reference
}

In order to correctly reference this scholarly work, feel free to copy and paste the following:

Chien Wang, Marta Luconi, Adriana Masi and Liliana Fernandez (2010). Silver Nanoparticles as Optical Sensors, Silver Nanoparticles, David Pozo Perez (Ed.), ISBN: 978-953-307-028-5, InTech, Available from: http://www.intechopen.com/books/silver-nanoparticles/silver-nanoparticles-as-optical-sensors

\section{INTECH}

open science | open minds

\section{InTech Europe}

University Campus STeP Ri Slavka Krautzeka 83/A 51000 Rijeka, Croatia Phone: +385 (51) 770447

Fax: +385 (51) 686166 www.intechopen.com

\section{InTech China}

Unit 405, Office Block, Hotel Equatorial Shanghai No.65, Yan An Road (West), Shanghai, 200040, China 中国上海市延安西路65号上海国际贵都大饭店办公楼405单元 Phone: +86-21-62489820

Fax: +86-21-62489821 
(C) 2010 The Author(s). Licensee IntechOpen. This chapter is distributed under the terms of the Creative Commons Attribution-NonCommercialShareAlike-3.0 License, which permits use, distribution and reproduction for non-commercial purposes, provided the original is properly cited and derivative works building on this content are distributed under the same license. 